\title{
A Case Study on Pre-service Secondary School Mathematics Teachers' Cognitive-metacognitive Behaviours in Mathematical Modelling Process
}

\author{
Meryem Özturan Sağirli
}

Faculty of Education, Erzincan University, Turkey

Copyright $(2016$ by authors, all rights reserved. Authors agree that this article remains permanently open access under the terms of the Creative Commons Attribution License 4.0 International License

\begin{abstract}
The aim of the present study is to investigate pre-service secondary mathematics teachers' cognitive-metacognitive behaviours during the mathematical problem-solving process considering class level. The study, in which the case study methodology was employed, was carried out with eight pre-service mathematics teachers, enrolled at a university in Erzincan, Turkey. We collected data via think aloud protocols in which metacognitive supports are provided and not provided and with unstructured metacognitive protocols related to the process. The metacognitive support provided to the pre-service teachers and this case caused an increase in the numbers of cognitive-metacognitive behaviours in class level in general. Any pattern was not encountered for the sequences of cognitive-metacognitive behaviours in the process of mathematical modelling during the stages in which metacognitive support was given and was not given but some little patterns were detected. It was noticed that there was no relationship with respect to the metacognitive support and without metacognitive support between and frequencies of cognitive-metacognitive behaviour mathematical modelling progress. The 1 st and 2 nd grade-pre-service teachers claimed that the metacognitive support contributed to them such factors as understanding and detailing, the 3rd and 4th graders expressed that it enabled them to follow, reach alternative ways of solution. The participants, during the stage in which the metacognitive support was provided, demonstrated more success during the process of mathematical modelling compared with the first stage.
\end{abstract}

Keywords Metacognition, Cognitive-Metacognitive Behaviours, Mathematical Modelling, Mathematical Modelling Process, Pre-service Mathematics Teachers

\section{Introduction}

Metacognition, which is one of the most talked about and mentioned concepts [54], its being noticed and using it dates back to 557 B.C. [31]. This concept entered in the literature in 1976 by Flavell [33] (p.232) as the definition of 'metacognition refers to one's knowledge concerning one's own cognitive processes and products or anything related to them'. The researchers related to this concept in time as the following examples have carried out many definitions;

- It was defined as: individuals' having knowledge about their cognitive functions and arranging these cognitive functions and this definition, at the same time, is the answer of questions 'what do individuals know about their own cognitive functions and how do they arrange their cognitive activities throughout any task performance by [25]'.

- Individuals' knowledge about their own cognitive processes to achieve a certain goal and their observing-arranging these cognitive processes [54]

- A multi-dimensional skill set including thinking about thinking [46]

As these definitions relevant to metacognition are investigated, it can be noticed that knowledge related to the cognition and arrangements to the cognition are common in all definitions. One of the two main parts of metacognition, which seems to be different but highly interrelated, is cognitive knowledge, and the knowledge of cognition consisting of beliefs [36]. The knowledge of cognition, which is also called as metacognitive knowledge, is knowledge that individuals have about their weaknesses as a problem solver or learner, or their own cognitive skills of knowing where, how and why they are to apply a strategy [25]. The second main part of metacognition is regulation of cognition depending on checking and arranging cognitive events [36]. The regulation of cognition is related to the metacognitive skills, which consist of observing and arranging activities to which individuals apply during problem solving and learning process [25]. While the metacognitive knowledge are mostly declarative knowledge depending on the interaction between three features of 
individual, task and strategy, metacognitive skills are mostly procedural knowledge concerning the arrangements of problem solving and learning activities [52].

Discovering the instructional effects of these two significant components of metacognition caused metacognition to be studied in other disciplines. As one of the disciplines is mathematics, and because of metacognition contribute to the acquisition of things to be learned, making it meaningful and applying it, that it has a significant role in learning mathematics by the students were emphasized by $[9,36,42]$. Moreover, deficiency of metacognitive skills is considered to be one of the main reasons of students' failure in mathematics $[21,24]$.

It is thought that adding such educational activities enable students to make their own choices, make their own decisions, follow and check these decisions, interpret the results of their decisions in teaching-learning process may contribute their metacognitive skills development. Because, these behaviours consisting of arranging, observing, planning and evaluating are related to metacognition associated with individuals' thoughts are related to their own cognitive processes rather than cognition [54]. Problem solving process, as it consists of those sorts of educational activities, is a former activity among the other ones that can be used for the development of metacognition. Mathematical modeling, in which unstructured problems are used in its process [65], can also be used with the same purpose. In addition to the problem solving activities, as mathematical modelling activities enable students not only solve a problem but also configure the problem and check, help students more than problem solving $[28,63]$. That is, while even a simple problem solving experience has four steps of modelling process, mathematical modelling problems consist of multi-modelling processes, in short[74].

The stages named as modelling periods should be considered as steps; carrying a problem from real life to the mathematical world and converting it to a mathematical problem, developing an appropriate model for the problem, performing mathematical operations to solve the model, and interpreting the solution to the real life $[41,56,58]$ and as a periodical or repetitive process [73]. So, this process of solving problems gathered from real life is named as mathematical modelling [34]. Therefore, this dynamic structure of mathematical modelling process enabling the students to explain their mathematical thinking, testing and correcting through revising [33] gives them more opportunities to demonstrate their metacognitive behaviours.

These interrelations among problem solving, modelling and metacognition stated as topics of many studies. These researches, firstly, started with the metacognitive researches which are driving forces in problem solving by Lesh, Silver and Schoenfold in 1982 [27]. Metacognition, since the mentioned date, has become one of the most the most researched two topics (the other is problem solving) in mathematics [8] and still remains popular. As the studies on metacognition carried out in mathematics are investigated, it is noticed that metacognition is the largely focused topic among those studies.

That is, during a task of problem solving, solvers, before applying investigating a problem, understanding it, evaluating the sufficiency of given data, organizing these data, making a plan for solving and applying the plan, they come across with tasks such as predicting its usefulness then, applying this plan and evaluating the validity of its results $[8,10,57,59]$. But, it is extremely difficult to explain these activities during the problem solving with cognition consisting of only knowledge organization and thinking [31]. Individuals, in their experiences of problem solving-mathematical modelling, can be better problem solvers by facing them with metacognition training and increasing or powering their metacognition $[4,16,19,57,58,59,61,62]$. Veenman[53] stated that, in acquisition and teaching of a metacognition effectively, metacognition training being integrated to the relevant topic rather than a general perspective is one of their basic principles. It was pointed out that the direct and obvious metacognitive training rather than those given indirectly, are more beneficial to maintain metacognitive thinking and skills $[12,13,67]$. Because, one of the most effective ways to activate metacognition is to give directions to the students and provide their compliances to the learning process encourage their prudential thoughts [81]. The metacognition support is given under the control of teachers, systematically and organized, it will have a significant role on learning performance.(22, 26,48,54,82]. In addition, Lester, Garafalo \& Kroll [26] pointed out three roles of teachers seem to be different during the metacognition instruction but, at the same time, extremely relevant, a) as a metacognitive monitor, (b) as a facilitator of students' metacognitive awareness, and (c) as a model of a metacognitive-adopted problem solver. In some of the studies, giving participants different sorts of metacognition supports, variables such as problem solving process and its success were investigated. The samples of this situation, placed in the literature, [7,11, 20,21,26, 30,39, $43,51,53,66,68,77,29]$ in addition, most of those studies were carried out with 3 th-12th graders in secondary education. In terms of the teachers and pre-service teachers, studies exist in literature as follows.

In some of the carried studies, teachers were observed in classroom and it was claimed that they had significant role in students' gaining metacognition skills $[1,75,78]$. Yet, the facts that teachers have little knowledge about metacognition, their answers to the questions about the metacognition were not more than It is independent learning, and they could not answer the question of how can metacognition be applied, are among the results of the studies [17,55]. In another research, it is pointed out that teachers enthusiastic in teaching metacognition in their lessons, but they have not got the tools and possibilities to provide this.[54]. In addition, there are studies pointing out that to provide the metacognitive activations of teachers with developing a model consisting of the social and cooperative situations and with the help of this model provided the metacognitive activations of them [82]. Teachers' knowledge and 
awareness about their own learning processes are extremely crucial for both in terms of being a good model for their students and teaching these behaviours to their students [18, 76]. Therefore, it is thought that investigating and learning metacognitive behaviours that the pre-service teachers have in problem solving process just before the service and the change of those behaviours supported with metacognition will be significant.

Takahashi \& Murata[81], in their experimental studies, compared an education activating metacognition with a problem-solving-based education in terms of the time, which the pre-service teachers, without any education, wasted on problem solving. As a result of the study, they reached a result that metacognition teaching has a function of activating metacognition in terms of understanding and managing problem solving process. In a study by Yimer and Ellerton [16], metacognitive behaviours that the pre-service teachers demonstrated during the problem solving process, without any education support, were analysed with the help of a five-stage-model consisting of engagement, transformation- formulation, implementation, evaluation and internalization. The results of the analysis indicated that the metacognitive behaviours of pre-service teachers in this five-stage model were not linear or single-directional. A study was carried out by Demircioğlu, Argün and Bulut [32] aiming to evaluate the metacognitive behaviours of pre-service secondary school mathematics teachers in problem solving process. From the results of the study, it was reached that there was no relation between the academic success of pre-service teachers and the frequency of demonstrated metacognitive behaviour, yet, it was realised that the type of the problem affected this frequency. Wilburne [40] investigated the effects of metacognitive strategy education on problem solving successes of secondary school pre-service mathematics teachers and expressed that the support provided increase in the pre-service secondary school mathematics teachers' levels of problem solving success.

It was noticed that although the metacognitive competencies in the process of mathematical modelling [44, $45,64,74]$ were significant in mathematical modelling, studies on this topic were mainly focused on cognitive dimension [69, 70]. Therefore, researches enabling the development of metacognitive behaviours in mathematical modelling process will contribute to the process. Accordingly, in the study, it is aimed to investigate the differences of cognitive-metacognitive behaviours demonstrated by pre-service teachers in the occasions with and without outer support. In accordance with this aim, following research questions were asked;

1. Do the numbers of cognitive -metacognitive behaviours demonstrated by pre-service teachers within the stages of mathematical modelling vary in terms of the class variable in the occasions with and without metacognitive support?

2. Does the sequence of demonstrated cognitive-metacognitive behaviours by pre-service teachers in mathematical modelling processes vary according to the occasions with and without metacognitive support in terms of the class variable?

3. How do the pre-service teachers evaluate the mathematical modelling processes in terms of with and without metacognitive support?

\section{Materials and Methods}

In this study, a case study from, considering the qualitative research models, was adapted in order to handle the problem deeply $[38,71,79]$. In this study, the participants' cognitive-metacognitive activities in mathematical modelling were tried to handle deeply based on this method.

\subsection{Participants}

This study was carried out with eight pre-service teachers who were students at the department of secondary school mathematics teacher training at a university, which is located in a medium sized province in the east of Turkey. In the study group, there were two students from the first, second, third and fourth grades.

The process of constituting the study group was completed in two stages. In the first stage, the research university was determined via the convenience sampling that enables constituting the research group among the ones who can easily be reached and economical in terms of time - money-effort etc. [50]. In the second stage, typical situation sampling method allowing some previously determined significance criteria, and preferred for enabling all the situations to be studied and revised [50] was determined. In determining the participants in this study, the criteria of constituting the participants can be listed as follows;

1. That the general average success of participants should be neither high nor low, that is, at medium level

2. That their self-expression skills should be at good level

3. That their readiness level on mathematical model and modelling should be same.

The first of those was considered as a criterion for a pre-service teacher who has an average success rather than one with high success or one with low success level in terms of demonstrating metacognitive behaviours during problem solving process and 8 participants from all of the grades were determined with the help of class advisor.

The participants' expressions their procedures during the study are crucial for the validity of the study. The second criterion is significant for this reason and to provide this criterion, the views of the lecturers in the department were taken into consideration. Along with these opinions, the numbers of participants were reduced from 8 to 5 .

The third criterion was considered in terms of creating 
same conditions before the participants' starting problem solving and in order to investigate this situation, the following process was taken into consideration:

A form consisting of two mathematical modelling problems was given to the pre-service teachers to read (They were told they could read as much as they wanted). This process continued about 5 minutes. After the feedback from the pre-service teachers about finishing reading, they were asked if they had encountered with this sort of problems before as first question. Then as a second question, the pre-service teachers were asked a question as; 'If you had to solve this problem, what sort of procedure would you follow?' After asking this question, the pre-service teachers were asked to make operations and they were asked to tell only their ideas of solution. As third and last question, the pre-service teachers were asked; 'Have you heard the terms of mathematical model, mathematical modelling, mathematical modelling problem before, if you have, can you explain?' At the end of this process, the participants which were previously 5 in each grade were reduced to 2 and totally 8 participants were determined for the study. Then, the participants were told and informed about the aim and topic of the study, they were ensured to participate in this study voluntarily.

\subsection{Data Collection Instruments and Data Collection}

The verbal protocol technique was applied as a data collection tool in the study. A mathematical modelling problem was given to the participants to solve during the protocol and they were asked to solve it. It is predicted that, these sorts of problems, with the nature of their structures, giving the necessary mathematical data for the target and solution in a closed form [23] enable using metacognitive knowledge and skills during the problem solving process frequently.

Moreover, as it is indicated in Figure 1, considering the viewpoint of model and modelling as a parallel and interactive structure with the views on cognition and metacognition is considered as single-way and sequent - the same as the traditional definitions of metacognition [72]. That is, according to this point of view, throughout the process of given problem situation, the amount of energy, which the individual spent on cognitive activities, is the most important factor which effects the size of relevant metacognitive process. Therefore, some information is given related to the metacognitive activities which are demonstrated during the solving processes of modelling problems as in any problem solving process, can be monitored along the cognitive- metacognitive frame but this frame cannot be represented in a hierarchy.

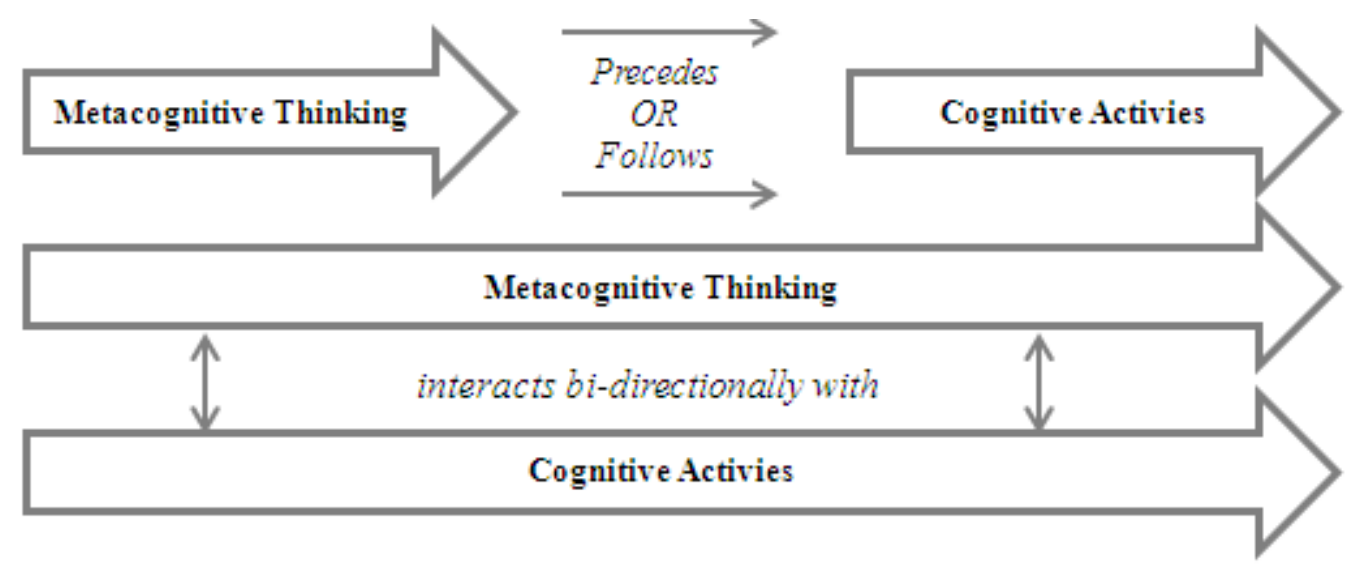

Figure 1. Relationships between metacognitive and cognitive 
The mathematical modelling problem to be used in the research was decided as follows: Firstly, necessary literature scanning was carried out with three researchers, who are proficient in the field under discussion, many articles and theses on mathematical modelling were investigated and a question pool was constituted. The modelling problems existing in this pool, the grade they used for, the context they were used, the frequency of using, their difficulty levels were also considered and, therefore, as modelling problem a baseboard question was chosen. Moreover, the baseboard problem consists of five sub-problems, each problem aims to include keeping different things. With this aspect, it has a structure, which gives detailed information about the process compared with a single problem. After the pilot study, final decision was made about the chosen modelling problems were suitable. The baseboard problem is as follows;

Baseboard Problem: Ahmet wants to cover his room with basement. Firstly, in order to make covering on the walls and floors, he will have tacked baseboards around the room. The width of the room is $21 \mathrm{~m}$ and its length is $28 \mathrm{~m}$. The baseboards are 10 and $16 \mathrm{~m}$ in length.

1) How many of each baseboard does he need to buy to cover around the room?

2) If Ahmet wants to make as few joints as possible, how many of each baseboard does he need to buy?

3) If Ahmet wants to waste as few baseboards as possible, how many of each baseboard does he need to buy?

4) If $16 \mathrm{~m}$ board is $1.25 \$$ and $10 \mathrm{~m}$ board is $1.10 \$$, how many of each board does he need to buy with little money?

5) $16 \mathrm{~m}$ boards are on sale and as its new cost is $0.85 \$, 10$ $\mathrm{m}$ boards' costs are same, that is $1.10 \$$. If Ahmet wants to spend the least money, how many of each board does he need to buy?

The information related to data collection tools applied in the research is as follows in order;

1. Think-aloud Protocols: Think aloud protocols are on-line measuring techniques which ask individuals tell-describe their thoughts verbally while they are working on a task (problem) [3, 48]. Think-aloud protocols provide the richest data which can be obtained about metacognitive processes throughout learning, as they are related to gathered metacognitive behaviours [3] during a learning task [52]. When the role of metacognition in predicting learning performance as a key variable was considered [1,9], moreover, and the fact that the metacognition explain $37 \%$ of learning variance during a learning task was considered [54] it was decided that the most appropriate tool for the aim of this study was think-aloud protocols.

This protocol was carried out in two stages as with and without metacognitive support. The second stage, in which the protocol was carried immediately after the first stage, in order not to encounter with troubles endangering the validity of the study by affecting the participants' process (the participants' talking with somebody about the solving procedure of the problem, making investigation, producing new solutions, the weakening control of interviewer and participant on the problem solving process etc.). An environment enabling the participants no corruption in their attention in terms of noise and comfort during the process was created. Some documents, which they can use in each stage, were prepared for the participants in order to work comfortably on the problems. Each participant was coded as K.1.1, K.1.2 etc. in each grade and was prepared before the protocol. After all of the preparations, in order to determine the possible problems in practice, a pilot study was carried out with a pre-service teacher at the third grade.

During the first stage of the protocols, no metacognitive support was given to the participants by the researchers. Thus, it was aimed to investigate the cognitive-metacognitive behaviours demonstrated by the participants during the solving processes of mathematical modelling problems without any support. The participants were informed about the goals of the research at the beginning, that the most significant point for the research was the description or telling of what they think during the process, each idea they thought up, all the activities they drew, every symbol they made, equation, figure, graph... etc. that should be described were reminded to the participants. Furthermore, it was reminded to the participants that the period of the solving process is not an important factor, so the participants were provided not to feel under pressure thinking of 'I have to be the fastest solver'. The end of the first stage was decided with the expressions by the participants as 'enough, finished'. The think-aloud protocols with the participants changed as 40-100 minutes. The researchers did not interrupt with any verbal, factual or symbolical interventions, which would affect the problem solving process of the participants during the period. Yet, during the situations in which the participants continued the solving process but preferred keeping silent rather than describing the solving process verbally, the researchers warned them expressing: ' Could you tell us what you dothink here'.

At the second stage of the protocols, the participants were supported with metacognition by the researchers. Thus, it was aimed to investigate the metacognitive activities of participants in the solving process of mathematical modelling problems when the participants got metacognitive metacognition support. The metacognition support here, was used in terms of asking questions directing the participants in situations in which they can demonstrate metacognitive behaviours. With this aim, following questions were asked to the pre-service teachers in each sub-problems of the baseboard problem?

Can you read the question...................? Can you describe what you understand from this question? That is, what do you want to mean?

What do you have to do in this occasion? Have you got a 
plan for this? What's you plan? Which strategy do you think to follow?

Does it work? Was it useful? Did you reach the solution?

Do you think this result is correct? Have you convinced with this result? Is it the only solution for you? I wonder if reach the solution with another procedure?

These questions were formed depending on the three metacognitive questions of Schoenfeld[11] and the principles of Veenman[51]. These questions mean the awareness of individuals about what they know and when and how they apply this knowledge [83]. So, the questions asked in the study were related to the behaviours of metacognition knowledge and arrangement, which are two significant components of metacognition. The questions under discussion, even if they were asked sometimes in different forms according to the problem solving processes of the participants, it was taken care of not losing their content meanings.

While the second stage of think-aloud was being carried out, the documents consisting of the data related to the solution of the problem and used by the participants in the first stage were placed in which the participants can easily see. The think-aloud protocols with the participants continued for 25-60 minutes.

2. The Protocol After Thinking Aloud Protocols: The third stage of the protocols has unstructured characteristics. The protocol is related to the participants' comparing the solving processes of mathematical modelling problem in the first and second stages. Thus, the participants were asked to evaluate the first and second stages of the think-aloud protocols in terms of problem solving process. The period of the protocol differed between 3-7 minutes.

The data in the study were collected thanks to the protocols mentioned above. The study was carried out with two different kinds of protocols. All of the protocols were recorded with a video camera after the permissions of the participants were taken. The collected data through the think-aloud protocols with/ without metacognitive supports and the protocols after the think-aloud protocols were sent to the computer system and prepared for the analysis process

\subsection{Data Analysis}

In the analysis of the collected data, various analysis methods were applied. During the study, to provide the protocols with the participants to be long-term, applying to experts views who are skilled in each process of the research (expert analysis), showing the documents of the protocols to the participants and taking the participants' confirmation (participant confirmation), placing the protocols between the participant-researcher related to the codes and themes emerged during the study (detailed description), the criteria of sampling selection, that the research reports being investigated by different researchers (verification and validation analysis) were considered. The analysis process related to each problem can be detailed as follows.

For the analysis of the think-aloud protocols, firstly, the documents of protocols were presented to the participants' investigation. For the transcripts of think-aloud protocols, descriptive analysis was applied. According to this analysis, the collected data were summarised according to the previously determined themes and interpreted and the aim is to present the gathered data to the readers in an arranged and interpreted form [14]

For the conceptual framework required in the process of descriptive analysis, firstly the frameworks in the literature were investigated. The researchers have developed many models and frameworks during the period that enable the individuals to describe their cognitive and metacognitive activities during the process of mathematical problem solving;

- $\quad$ read, analyse, explore, plan, implement, verify [9],

- orientation, organization, execution, verification [36],

- understanding, analyse, planning, exploring, implementing, verifying [4,5],

- engagement, resources, executive behaviours, beliefs [80],

- $\quad$ report, discussion, monitoring, self-evaluation [60],

- orientation, planning, executing, checking [49],

- engagement, transformation, formulation, implementation, evaluation, internalization [15],

In this study, the framework developed by Garofalo\& Lester [36],was applied. The basic reason for choosing this framework is that the stages, which exist within the framework, are substantially coincided with the mathematical modelling cycles. This framework, according to the aim of the study is used as follows: The four heading placed in cognitive-metacognitive framework as orientation, organization, execution and verification, were named as the themes of 1,2, 3 and 4 . The behaviours under these themes were associated with the letters orderly as A, B, C, D and each behaviour was categorised as $1 \mathrm{~A}, 1 \mathrm{~B}$...etc. In order to accommodate these labels to the transcripts, the researcher and three experts from the field of mathematical instruction and the draft codes read all of the transcripts and indicators, which represent the meaning of relevant label, were determined. These draft codes and indicators were used for testing for the analysis of some transcripts and their final forms were prepared to use in the analysis of other transcripts. In order to analyse the cognitive-metacognitive activities, which the participants demonstrated during the solving process of baseboard problem within the scope of the study, the final form of the framework is indicated in Table 1. 
Table 1. The cognitive-metacognitive behaviour framework applied in the analysis

\begin{tabular}{|c|c|c|c|c|}
\hline \multicolumn{2}{|c|}{$\begin{array}{l}\text { Theme and } \\
\text { Categories }\end{array}$} & Codes & Indicator & Sample Situation \\
\hline \multicolumn{5}{|c|}{ Strategic behaviour to assess and understand a problem } \\
\hline \multirow{5}{*}{ Organization } & $1 \mathrm{~A}$ & Comprehension strategies & $\begin{array}{l}\text { Reading again, underlining the sentences, } \\
\text { taking short notes (given, not requested), } \\
\text { self-description of the problem }\end{array}$ & $\begin{array}{c}\text { Firstly, we talk about a place which is } 21 \mathrm{~m} \\
\text { width } 28 \mathrm{~m} \text { length. }\end{array}$ \\
\hline & $1 \mathrm{~B}$ & $\begin{array}{l}\text { Analysis of information and } \\
\text { conditions }\end{array}$ & $\begin{array}{l}\text { Self-talks, writings, trying to understand } \\
\text { the concepts used in the problem }\end{array}$ & $\begin{array}{l}\text { Here says as less addition as possible. } \\
\text { What do the baseboards mean? I do not } \\
\text { understand. }\end{array}$ \\
\hline & $1 \mathrm{C}$ & $\begin{array}{l}\text { Assessment of familiarity } \\
\text { with task }\end{array}$ & Comparing the similarities & $\begin{array}{l}\text { Here, then this is the changing aspect of the } \\
\text { problem. }\end{array}$ \\
\hline & $1 \mathrm{D}$ & $\begin{array}{l}\text { Initial and subsequent } \\
\text { representation }\end{array}$ & $\begin{array}{c}\text { Drawing shapes such as table, graph, } \\
\text { pictures }\end{array}$ & Let's draw the room. Write the dimensions. \\
\hline & $1 \mathrm{E}$ & $\begin{array}{l}\text { Assessment of level of } \\
\text { difficulty and chances of } \\
\text { success }\end{array}$ & $\begin{array}{l}\text { The gestures, mimics and comments about } \\
\text { the easiness and difficulty of the problem. }\end{array}$ & $\begin{array}{l}\text { This is actually complex. } \\
\text { I didn't understand the problem. }\end{array}$ \\
\hline \multicolumn{5}{|c|}{ Planning of behaviour and choice of actions } \\
\hline \multirow{3}{*}{ Organization } & $2 \mathrm{~A}$ & $\begin{array}{l}\text { Identification of goals and } \\
\text { sub goals } \\
\end{array}$ & $\begin{array}{c}\text { Self-describing the requests as an aim, } \\
\text { determining a strategy }\end{array}$ & $\begin{array}{l}\text { My aim is to calculate it with minimum } \\
\text { cost, }\end{array}$ \\
\hline & 2B & Global planning & Providing a way map for the solution & I should use more pieces of $16 \mathrm{~m}$ boards \\
\hline & $2 \mathrm{C}$ & $\begin{array}{c}\text { Local planning (to } \\
\text { implement global plans) }\end{array}$ & $\begin{array}{l}\text { Further customizing and minimizing the } \\
\text { drawn map of way }\end{array}$ & $\begin{array}{c}\text { I should use } 7 \text { pieces of } 16 \mathrm{~m} \text { boards and } 5 \\
\text { pieces of } 10 \mathrm{~m} \text { boards }\end{array}$ \\
\hline \multicolumn{5}{|c|}{ Regulation of behaviour to conform to plans } \\
\hline \multirow{3}{*}{ Execution } & $3 \mathrm{~A}$ & $\begin{array}{l}\text { Performance of local } \\
\text { actions }\end{array}$ & Making mathematical calculations & $7 \times 0.85=5.95$ \\
\hline & 3B & $\begin{array}{l}\text { Monitoring of progress of } \\
\text { local and global plans }\end{array}$ & $\begin{array}{l}\text { Turning back to previous operations and } \\
\text { revising the procedure }\end{array}$ & $\begin{array}{c}\text { I have used } 5 \text { pieces of } 10 \mathrm{~m} \text { boards for its } \\
\text { width } \\
\text { I have used } 7 \text { pieces, it costs } 1 \text { lira, I have } \\
\text { used } 8 \text { pieces, which are } 2 \text { liras. }\end{array}$ \\
\hline & $3 \mathrm{C}$ & $\begin{array}{l}\text { Trade-off decisions (e.g., } \\
\text { speed vs. accuracy, degree } \\
\text { of elegance) }\end{array}$ & $\begin{array}{l}\text { Making a decision statement relevant to } \\
\text { the results of the calculations }\end{array}$ & $\begin{array}{l}\text { Totally, to sum up, then, that is, I should use } \\
7 \text { of them. }\end{array}$ \\
\hline \multicolumn{5}{|c|}{ Evaluation of decisions made and of outcomes of executed plans } \\
\hline \multirow[t]{2}{*}{ Verification } & $4 \mathrm{~A}$ & Evaluation of execution & $\begin{array}{l}\text { Expressions, checking and evaluations } \\
\text { related to understanding the problem and } \\
\text { comparing the results of the chosen } \\
\text { strategy }\end{array}$ & $\begin{array}{l}\text { I realized that it costs much, I disregard this, } \\
\text { that is definitely the correct answer }\end{array}$ \\
\hline & $4 \mathrm{~B}$ & Evaluation of execution & $\begin{array}{l}\text { The check and evaluations of the reached } \\
\text { solution, crosscheck and alternative ways } \\
\text { of solutions }\end{array}$ & $\begin{array}{c}\text { We have made an operational mistake, thus } \\
\text { we were able to check it. Another way of } \\
\text { solving is... }\end{array}$ \\
\hline
\end{tabular}

Table 1 was considered as a base for the analysis of each participant transcripts included in the study. For instance, if a transcript was labelled with $2 \mathrm{C}$ that means it belongs to the theme no. 2 category no. C. The meaning of $2 \mathrm{C}$ label is constituted with the combining the meanings of theme 2 and the category C. For instance, the theme number 2, in sum, means; making a plan for the solution of the problem, the category number $\mathrm{C}$ means; making special plans, the labelling $2 \mathrm{C}$ means making special plans, which can be applied in the solution of the problem. In the transcript analysis of the think-aloud protocols, in order to provide an integrity, thus, making the analysis more reliable the points that have been considered throughout the analysis are summarised and illustrated below.

- Sentences and clauses were coded considering the solving process of the problems that they related to. During the protocol with metacognitive support, while K.2.2 coded participant was solving the 3 rd problem, he expressed that, 'for $28 \mathrm{~m}$, let's use $16,2 \mathrm{C}$ is 4 from one side and 4 from the other side, $3 \mathrm{~A}$ totally 8 pieces left over, said 3C' with his clause; 'totally 8 left over' he put restriction in the third question saying: 'provided the least of wasting', thus, considering the expressions, it was coded as $3 \mathrm{C}$.

- Each clause constituting the sentences was analysed one by one. K.1.1 coded participants' expression, in protocol with metacognitive support, while solving the 2nd problem as 'If I use 1 piece of $16 \mathrm{~m}, 2 \mathrm{C}$, there remains $8 \mathrm{~m} 3 \mathrm{~A}$, no there are $12 \mathrm{~m} 4 \mathrm{~B}$, if I used 1 more pieces of $16 \mathrm{~m} 2 \mathrm{C}$, we will use $12 \mathrm{~m}$ of them $3 \mathrm{~A}$, then, here is 1 joint $3 \mathrm{~A}, 1$ more joint opposite, totally I have used 4 pieces of $16 \mathrm{~m}, 3 \mathrm{C}^{\prime}$ can be given as an example to this situation.

- As the room described in the study is rectangular, while the participants expressing the required numbers of baseboards, they mostly specified separate results 
for its width and length then stated the numbers of the baseboards that they will use for the entire room. Each sentence in which the participants expressed the numbers of the baseboards used for the width and length of the room, as the each sentences expressing the numbers of the baseboards used for the entire room, were coded as $3 \mathrm{C}$. In the protocol with metacognitive support, during the K.3.1 coded participant was solving the 5 th problem, the expressions as, 'That is, I used 3 pieces of $16 \mathrm{~m}$ is enough for its width, 3C' can be given as an example to this situation. Yet, $1 \mathrm{~A}$ coded participant, in solving the 2nd problem with metacognitive support used the expression as: 'We have made totally 6 joints, 2 in length and 4 in width, said,3C', as the results of width and length used for the general result, they were coded as not 3 of $3 \mathrm{C}$ but 1 of $3 \mathrm{C}$.

- Because of the rectangular shape of the room described in the problem used in the study, throughout the protocols both with and without metacognitive support, after the participants had finished the operations related to the width and length of the room, they frequently used the expressions as: 'this is same for the opposite wall', 'the above will also be same to this'. These expressions and all of the sentences, which are same in meaning with these expressions, were evaluated within the scope of $2 \mathrm{C}$.

- The meaning of the sentences was taken into consideration. For instance, while a transcript as 'It may be more appropriate to use all the boards from 16.', was coded as $2 \mathrm{C}$, as the aims were suitable for the planning of procedure, in general, the transcript 'If I use all of them from $16 \mathrm{~m}, 2 \mathrm{~m}$ left over, this is disadvantageous for me' was coded orderly as $2 \mathrm{C}, 3 \mathrm{~A}$, $4 \mathrm{~A}$.

- If the answers do not include a definite determination to the questions asked by the researchers in metacognitively supported protocols that means; the coding will not applied. In a metacognitive supported protocol, the answer of K.3.2 coded participant 'I have no idea now' to the question, during the process solving the $3 \mathrm{rd}$ problem, 'Is there a way of solution in which there is no boards left?' can be given as examples for this situation.

- In metacognitive supported protocols, participants, after expressing the result of the problem, were asked some questions by the researchers as 'I wonder if another way of solution can give you this result' or 'Do you want to operate through a different way'. Although the answers related to this question by the researcher seems to be appropriate to the code of $3 \mathrm{C}$ as it was an alternative way of solution, it was coded as 4B. While the K.2.2 coded participant, in a protocol with metacognitive support, was solving the 2nd problem, the expression of " 6 pieces of $16 \mathrm{~m}$ and 1 piece of $10 \mathrm{~m}$ also give the solution $4 \mathrm{~B}, 8$ pieces of $16 \mathrm{~m}$ gives the solution, too. 4B' can be given as an example to this situation. In this transcript, as the participant suggested two different way of solving, 4B code was used twice.

The data analysis process was carried out with two experts studying simultaneously and independently. For the think-aloud protocols in whit metacognitive support was given and was not given, the numbers of consensus and disagreement were determined and the reliability of the research was calculated using the formula of Miles and Huberman [47] Reliability = Consensus / (consensus + disagreement).

At the end of the coding, for the think-aloud protocols without metacognitive support, the reliability was found as $90 \%$. In $90 \%$ of the coding direct consensus was provided, $7 \%$ of them an agreement was provided in one code of the two researchers, $1,3 \%$ of them a coding was decided although none of the two researchers had been coded, 1,7\% of them, although both of the researchers had coded, it was decided not to make coding, $0,1 \%$ of them a code which was completely different from the codes of the two researchers was used.

For the think-aloud protocols with metacognitive support, the reliability was found as $85 \%$. In $85 \%$ of the coding a direct consensus was provided, $12 \%$ of them an agreement was provided in one code of the two researchers, $0,4 \%$ of them a coding was decided although none of the two researchers had been coded, 2,3\% of them, although both of the researchers had coded, it was decided not to make coding, $0,4 \%$ of them a code which was completely different from the codes of the two researchers was used. In qualitative researches, that the consensus being over $70 \%$, is regarded adequate in terms of the reliability of the research[47]. The findings whose reliabilities were provided are shown in tables and graphs using frequencies and percentages.

For the analysis of the mathematical modelling stages the steps in which Voskoglou[56] described the mathematical modelling process were determined as a basic framework. The basic reason for choosing this framework is that Voskoglou[56] describes the mathematical modelling process steps in an analytical way mostly, that gives the possibility to turn-back within the process and the content of this framework provides the opportunity to couple with used cognitive-metacognitive framework. Voskoglou[56] stated that mathematical modelling process consists of five main stages starting with S1 and finishing with S5.

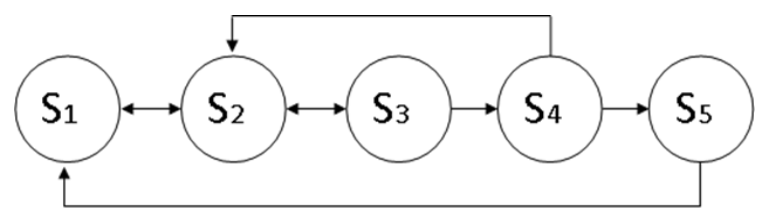

Figure 2. Voskoglous' mathematical modelling stages

These stages are described as follows: S1: Understanding the problem: Realizing the content and limits of the real problem situation and expressing them. S2: Forming it to mathematics: It means building the model prepared for 
mathematical procedures, in other words, formulizing the real situation. S3: Solving the Model: Doing appropriate mathematical operations. S4: Checking the Model: Before the interpretation of the model, comparing the adequacy of the mathematical model with the mentioned problem. S5: Interpretation: In order to respond the problem, adapting the model to the real situation and interpreting the final mathematical results.

Considering the contents of this framework, it was determined that the codes as $1 \mathrm{~A}, 1 \mathrm{~B}, 1 \mathrm{C}, 1 \mathrm{D}$ and $1 \mathrm{E}$ used in cognitive-metacognitive framework was used to represent the stage of $\mathrm{S} 1$ in mathematical modelling process; the codes as $2 \mathrm{~A}, 2 \mathrm{~B}$ and $2 \mathrm{C}$ to represent the stage of $\mathrm{S} 2$, the codes as $3 \mathrm{~A}, 3 \mathrm{~B}$ and $3 \mathrm{C}$ to represent the stage of $\mathrm{S} 3$ and $4 \mathrm{~A}, 4 \mathrm{~B}$ codes to represent $\mathrm{S} 4$ and $\mathrm{S} 5$ stages. Therefore, an expert dealing with cognitive activities in mathematical modelling process was applied for to take opinion.

For the analysis of the protocols after the think-aloud protocols, the views of the participants were described. To do this, firstly, the transcripts of the protocols with the participants were constituted and applied the confirmations of the participants.

\section{Findings}

In this section, findings related to the sub-problems of the study are presented in order.

3.1. Findings Related to the Research Question of 'Do the numbers of cognitive-metacognitive behaviours demonstrated by pre-service teachers within the stages of mathematical modelling vary in terms of the class variable in an occasion with and without metacognitive support?'
In order to find answer to this sub-problem, the findings gathered during the occasions of with and without metacognitive support are presented in order considering the class level as follows.

\subsubsection{The Numbers of Cognitive-Metacognitive Behaviours} of K.1.1 and K.1.2 Coded Participants

The findings related to the numbers of cognitive-metacognitive behaviours demonstrated by the K.1.1 and K.1.2 coded participants during the stages with and without metacognitive support is indicated in Table 2.

As the Table 2 is investigated, it is noticed thatK.1.1 and K.1.2coded participants, during the stage of S1 modelling period, have used $1 \mathrm{~A}$ and $1 \mathrm{~B}$ coded behaviours most. It is noticed that, there is generally a reducing or equality the use of $1 \mathrm{~A}$ coded behaviour at the stage of the protocols with metacognitive support, yet an increase and equality was observed in 1B. 1E coded behaviour at the stage of S1, in the protocols without metacognitive support, and this participant has never demonstrated 1C-coded behaviour, in the protocols with metacognitive support. During the stage of S2, it was observed that the participants mostly demonstrated $2 \mathrm{C}$ coded behaviour and secondly demonstrated 2B coded behaviour. This behaviour has demonstrated increase generally in the protocols with metacognitive support (except for the 4th question of 1B). Mostly demonstrated behaviour by the participants during the stage of S3 was 3A coded behaviour and demonstrated increase in the protocols with metacognitive support. Mostly demonstrated behaviour during the stage of S4 was 4A coded behaviour and again its demonstration increased in general during the protocols with metacognitive support.

Table 2. The numbers of cognitive-metacognitive behaviours of K.1.1 and K.1.2 coded participants

\begin{tabular}{|c|c|c|c|c|c|c|c|c|c|c|c|}
\hline \multirow{3}{*}{$\begin{array}{l}\text { Modelling } \\
\text { circles }\end{array}$} & \multirow{3}{*}{ Coding } & \multicolumn{5}{|c|}{ K.1.1 } & \multicolumn{5}{|c|}{ K.1.2 } \\
\hline & & \multicolumn{5}{|c|}{ Sub-problems } & \multicolumn{5}{|c|}{ Sub-problems } \\
\hline & & 1 & 2 & 3 & 4 & 5 & 1 & 2 & 3 & 4 & 5 \\
\hline \multirow{5}{*}{ S1 } & $1 \mathrm{~A}$ & 4- 2 & $2-1$ & $2-1$ & $2-2$ & $1-1$ & $4-3$ & $1-2$ & $2-1$ & $2-2$ & $1-1$ \\
\hline & $1 \mathrm{~B}$ & 3- 6 & $3-6$ & $1-1$ & $1-1$ & $0-1$ & $2-8$ & $1-2$ & $1-3$ & $1-1$ & $0-3$ \\
\hline & $1 \mathrm{C}$ & $0-1$ & $0-3$ & $1-0$ & $1-1$ & $1-0$ & $0-0$ & $0-0$ & $0-0$ & $0-0$ & $0-0$ \\
\hline & $1 \mathrm{D}$ & $0-1$ & $0-2$ & $0-2$ & $0-0$ & $0-0$ & $2-1$ & $1-2$ & $1-0$ & $1-0$ & $1-1$ \\
\hline & $1 \mathrm{E}$ & $0-0$ & $0-0$ & $0-0$ & $0-0$ & $0-0$ & $0-0$ & $0-0$ & $1-0$ & $0-0$ & $0-1$ \\
\hline \multirow{3}{*}{ S2 } & $2 \mathrm{~A}$ & $0-1$ & $0-0$ & $0-0$ & $0-1$ & $0-0$ & $0-1$ & $2-2$ & $1-1$ & $0-1$ & $0-0$ \\
\hline & $2 \mathrm{~B}$ & $1-2$ & $0-3$ & $0-1$ & $0-1$ & $1-2$ & $0-1$ & $2-2$ & $0-2$ & $1-0$ & $3-2$ \\
\hline & $2 \mathrm{C}$ & $1-5$ & $2-10$ & $1-5$ & $2-4$ & $2-4$ & $3-4$ & $6-5$ & $3-5$ & $3-1$ & $3-5$ \\
\hline \multirow{3}{*}{$\mathrm{S} 3$} & $3 \mathrm{~A}$ & $1-2$ & $2-10$ & $1-5$ & $3-6$ & $2-5$ & $1-1$ & $3-6$ & $3-6$ & $6-1$ & $5-7$ \\
\hline & $3 \mathrm{~B}$ & $0-0$ & $0-1$ & $2-0$ & $0-1$ & $1-1$ & $1-5$ & $0-2$ & $0-1$ & $0-2$ & $0-0$ \\
\hline & $3 \mathrm{C}$ & $0-2$ & $2-6$ & $1-2$ & $0-3$ & $2-0$ & $4-5$ & $3-3$ & $1-1$ & $1-0$ & $3-1$ \\
\hline \multirow{2}{*}{ S4 } & $4 \mathrm{~A}$ & $1-5$ & $0-3$ & $1-6$ & $2-5$ & $2-3$ & $0-0$ & $1-2$ & $2-2$ & $1-4$ & $2-2$ \\
\hline & $4 \mathrm{~B}$ & $0-2$ & $0-5$ & $0-3$ & $1-3$ & $0-2$ & $0-9$ & $0-5$ & $0-1$ & $0-0$ & $0-1$ \\
\hline \multicolumn{2}{|c|}{ Total } & $11-29$ & $11-47$ & $10-26$ & $12-28$ & $12-19$ & $17-38$ & $20-33$ & $15-23$ & 16-12 & $18-24$ \\
\hline
\end{tabular}

For each sub-problem, the first column indicates the numbers of behaviours without the metacognitive support and the second column with the metacognitive support. 
K.1.1 and K.1.2 coded participants demonstrated totally 56-86 cognitive-metacognitive behaviours in the process of mathematical modelling in the stage without metacognitive support, and they demonstrated 149-130 cognitive-metacognitive behaviours in the stage with metacognitive support.

\subsubsection{The Numbers of Cognitive-Metacognitive Behaviours of K.2.1 and K.2.2 Coded Participants}

The findings related to the numbers of cognitive-metacognitive behaviours demonstrated by the K.2.1 and K.2.2 coded participants during the stages with and without metacognitive support are indicated in Table 3.

As the Table 3 is investigated, it is noticed that K.2.1 and K.2.2 coded participants during the stage of S1 modelling period, have used $1 \mathrm{~A}$ and $1 \mathrm{~B}$ coded behaviours most, It is noticed that, during the stage of S2, they demonstrated $2 \mathrm{C}$ coded behaviours most. $2 \mathrm{C}$ coded behaviour, in the protocols with metacognitive support increased in general (except for the 1st question of 2B). During the stage of S1, while 1C coded behaviour was never demonstrated in the protocols without metacognitive support, 1C coded behaviour is the least demonstrated behaviour during this stage. Mostly demonstrated behaviour by the participants during the stage of S3 is 3A coded behaviour and increased in the protocols with metacognitive support. The most demonstrated behaviours during the stage of $\mathrm{S} 4$ are $4 \mathrm{~A}$ and $4 \mathrm{~B}$ coded behaviours, however, it also increased with metacognitive support.

K.2.1 and K.2.2 coded participants demonstrated totally 8-83 cognitive-metacognitive behaviours in the process of mathematical modelling in the stage without metacognitive support, and they demonstrated 130-115 cognitive-metacognitive behaviours in the stage with metacognitive support.

Table 3. The numbers of cognitive-metacognitive behaviours of K.2.1 and K.2.2 coded participants

\begin{tabular}{|c|c|c|c|c|c|c|c|c|c|c|c|}
\hline \multirow{3}{*}{\multicolumn{2}{|c|}{$\begin{array}{l}\text { Modelling circles } \\
\text { and coding }\end{array}$}} & \multicolumn{5}{|c|}{ K.2.1 } & \multicolumn{5}{|c|}{ K.2.2 } \\
\hline & & \multicolumn{5}{|c|}{ Sub-problems } & \multicolumn{5}{|c|}{ Sub-problems } \\
\hline & & \multirow{2}{*}{$\frac{1}{2-1}$} & \multirow{2}{*}{$\frac{2}{1-4}$} & \multirow{2}{*}{$\frac{3}{1-2}$} & \multirow{2}{*}{$\frac{\mathbf{4}}{0-2}$} & \multirow{2}{*}{$\frac{5}{0-2}$} & \multirow{2}{*}{$\frac{1}{6-1}$} & \multirow{2}{*}{$\frac{2}{1-1}$} & \multirow{2}{*}{$\begin{array}{c}3 \\
1-1\end{array}$} & \multirow{2}{*}{$\frac{4}{2-1}$} & \multirow{2}{*}{$\frac{5}{3-2}$} \\
\hline & $1 \mathrm{~A}$ & & & & & & & & & & \\
\hline & 1B & $0-7$ & $0-3$ & $0-1$ & $0-1$ & $0-1$ & $4-5$ & $1-2$ & $0-2$ & $1-2$ & $2-0$ \\
\hline \multirow[t]{3}{*}{ S1 } & $1 \mathrm{C}$ & $0-0$ & $0-0$ & $0-0$ & $0-0$ & $0-0$ & $0-1$ & $0-0$ & $4-0$ & $0-0$ & $3-0$ \\
\hline & $1 \mathrm{D}$ & $2-1$ & $0-0$ & $0-1$ & $0-1$ & $0-1$ & $3-0$ & $1-0$ & $1-1$ & $1-0$ & $1-0$ \\
\hline & $1 \mathrm{E}$ & $1-1$ & $0-0$ & $0-0$ & $0-0$ & $0-0$ & $2-0$ & $0-0$ & $0-0$ & $0-0$ & $0-0$ \\
\hline \multirow{3}{*}{ S2 } & $2 \mathrm{~A}$ & $1-3$ & $0-0$ & $0-0$ & $0-0$ & $0-1$ & $0-2$ & $1-1$ & $0-0$ & $0-0$ & $2-0$ \\
\hline & $2 \mathrm{~B}$ & $0-0$ & $0-4$ & $0-0$ & $0-1$ & $0-2$ & $5-7$ & $0-0$ & $0-0$ & $2-3$ & $1-2$ \\
\hline & $2 \mathrm{C}$ & $0-11$ & $0-4$ & $0-2$ & $0-6$ & $0-6$ & $5-2$ & $2-4$ & $3-7$ & $2-3$ & $1-1$ \\
\hline \multirow{3}{*}{ S3 } & $3 \mathrm{~A}$ & $0-12$ & $0-4$ & $0-2$ & $0-6$ & $0-4$ & $2-11$ & $1-2$ & $2-7$ & $3-4$ & $0-1$ \\
\hline & $3 \mathrm{~B}$ & $0-1$ & $0-0$ & $0-1$ & $0-1$ & $0-2$ & $0-0$ & $0-0$ & $0-2$ & $0-1$ & $0-0$ \\
\hline & $3 \mathrm{C}$ & $0-0$ & $0-3$ & $0-1$ & $0-1$ & $0-0$ & $5-15$ & $2-4$ & $1-4$ & $1-2$ & $1-1$ \\
\hline \multirow{2}{*}{ S4 } & $4 \mathrm{~A}$ & $0-4$ & $0-1$ & $0-2$ & $0-4$ & $0-4$ & $0-4$ & $0-2$ & $1-1$ & $0-4$ & $0-0$ \\
\hline & $4 B$ & $0-4$ & $0-1$ & $0-3$ & $0-1$ & $0-0$ & $2-3$ & $0-2$ & $1-4$ & $0-1$ & $0-1$ \\
\hline \multicolumn{2}{|c|}{ Total } & $6-44$ & $1-24$ & $1-15$ & $0-24$ & $0-23$ & $34-40$ & $9-18$ & $14-29$ & $12-20$ & $14-8$ \\
\hline
\end{tabular}

For each sub-problem, the first column indicates the numbers of behaviours without the metacognitive support and the second column with the metacognitive support.

\subsubsection{The Numbers of Cognitive-Metacognitive Behaviours of K.3.1 and K.1.2 Coded Participants}

The findings related to the numbers of cognitive-metacognitive behaviours demonstrated by the K.3.1 and K.3.2 coded participants during the stages with and without metacognitive support are indicated in Table 4. 
Table 4. The numbers of cognitive-metacognitive behaviours of K.3.1 and K.3.2 coded participants

\begin{tabular}{|c|c|c|c|c|c|c|c|c|c|c|c|}
\hline \multirow{3}{*}{\multicolumn{2}{|c|}{$\begin{array}{l}\text { Modelling circles } \\
\text { and coding }\end{array}$}} & \multicolumn{5}{|c|}{ K.3.1 } & \multicolumn{5}{|c|}{ K.3.2 } \\
\hline & & \multicolumn{5}{|c|}{ Sub-problems } & \multicolumn{5}{|c|}{ Sub-problems } \\
\hline & & \multirow{2}{*}{$\begin{array}{c}1 \\
2-1\end{array}$} & \multirow{2}{*}{$\begin{array}{c}2 \\
2-2\end{array}$} & \multirow{2}{*}{$\begin{array}{c}3 \\
1-0\end{array}$} & \multirow{2}{*}{$\begin{array}{c}4 \\
1-4\end{array}$} & \multirow{2}{*}{\begin{tabular}{|c|}
5 \\
$2-1$
\end{tabular}} & \multirow{2}{*}{$\begin{array}{c}1 \\
4-3\end{array}$} & \multirow{2}{*}{$\begin{array}{c}\mathbf{2} \\
1-1\end{array}$} & \multirow{2}{*}{$\begin{array}{c}3 \\
2-1\end{array}$} & \multirow{2}{*}{$\begin{array}{c}4 \\
1-1\end{array}$} & \multirow{2}{*}{$\begin{array}{c}5 \\
0-1\end{array}$} \\
\hline & $1 \mathrm{~A}$ & & & & & & & & & & \\
\hline \multirow{4}{*}{ S1 } & 1B & $4-4$ & $3-1$ & $1-2$ & $0-0$ & $0-1$ & $7-4$ & $1-2$ & $1-1$ & $1-2$ & $0-0$ \\
\hline & $1 \mathrm{C}$ & $0-0$ & $0-0$ & $0-0$ & $0-0$ & $0-0$ & $0-0$ & $0-0$ & $0-0$ & $0-0$ & $0-1$ \\
\hline & $1 \mathrm{D}$ & $1-2$ & $1-0$ & $1-1$ & $1-0$ & $1-1$ & $4-1$ & $0-1$ & $0-1$ & $0-0$ & $0-0$ \\
\hline & $1 \mathrm{E}$ & $0-0$ & $0-0$ & $0-0$ & $0-0$ & $0-0$ & $0-0$ & $0-0$ & $0-1$ & $4-0$ & $0-0$ \\
\hline \multirow{3}{*}{ S2 } & $2 \mathrm{~A}$ & $4-0$ & $0-1$ & $0-0$ & $0-2$ & $0-0$ & $0-0$ & $0-1$ & $1-0$ & $0-0$ & $0-1$ \\
\hline & $2 \mathrm{~B}$ & $1-3$ & $2-1$ & $4-10$ & $0-7$ & $1-4$ & $7-1$ & $5-7$ & $0-0$ & $3-1$ & $0-1$ \\
\hline & $2 \mathrm{C}$ & $5-3$ & $6-6$ & $5-8$ & $3-2$ & $4-0$ & $12-2$ & $2-2$ & $0-0$ & $1-0$ & $0-0$ \\
\hline \multirow{3}{*}{ S3 } & $3 \mathrm{~A}$ & $5-0$ & $7-3$ & $8-12$ & $2-2$ & $1-1$ & $16-8$ & $5-3$ & $0-0$ & $2-3$ & $0-0$ \\
\hline & $3 \mathrm{~B}$ & $0-0$ & $5-1$ & $0-1$ & $0-2$ & $2-2$ & $0-0$ & $2-0$ & $6-1$ & $1-0$ & $0-0$ \\
\hline & $3 \mathrm{C}$ & $3-1$ & $7-8$ & $5-8$ & $2-4$ & $2-3$ & $9-1$ & $4-4$ & $3-0$ & $3-1$ & $0-1$ \\
\hline \multirow{2}{*}{ S4 } & $4 \mathrm{~A}$ & $0-2$ & $3-5$ & $1-3$ & $1-4$ & $1-2$ & $1-1$ & $2-3$ & $2-1$ & $1-2$ & $0-1$ \\
\hline & 4B & $0-4$ & $3-5$ & $0-8$ & $0-1$ & $0-1$ & $5-1$ & $2-1$ & $0-0$ & $1-0$ & $0-1$ \\
\hline \multicolumn{2}{|c|}{ Total } & $25-20$ & $39-32$ & $26-47$ & $10-28$ & $14-16$ & $48-22$ & $24-25$ & $15-6$ & $18-11$ & $0-7$ \\
\hline
\end{tabular}

For each sub-problem, the first column indicates the numbers of behaviours without the metacognitive support and the second column with the metacognitive support

As the Table 4 is investigated, it is noticed that K.3.1 and K.3.2 coded participants during the stage of S1 modelling period, have demonstrated $1 \mathrm{~A}$ and $1 \mathrm{~B}$ coded behaviours most, It is noticed that, during the stage of S2, they demonstrated $2 \mathrm{~B}$ coded behaviours most. During the stage of S1, the participant support never demonstrated 1C and 1E coded behaviours in the protocols without metacognitive. During the stage of S3, the most demonstrated behaviours by the participants are 3A and 3C coded behaviours. The most demonstrated behaviour by the participants during the stage of S4 are 4A and 4B coded behaviours and again increased in the protocols with metacognitive support.

K.3.1 and K.3.2 coded participants demonstrated totally 114-105 cognitive-metacognitive behaviours in order, in the process of mathematical modelling during the stage without metacognitive support, and they demonstrated 143-71 cognitive-metacognitive behaviours during the stage with metacognitive support.

\subsubsection{The Numbers of Cognitive-Metacognitive Behaviours of K.4.1 and K.4.2 Coded Participants}

The findings related to the numbers of cognitive-metacognitive behaviours demonstrated by the K.4.1 and K.4.2 coded participants during the stages with and without metacognitive support are indicated in Table 5.

Table 5. The numbers of cognitive-metacognitive behaviours of K.4.1 and K.4.2 coded participants

\begin{tabular}{|c|c|c|c|c|c|c|c|c|c|c|c|}
\hline \multirow{3}{*}{\multicolumn{2}{|c|}{$\begin{array}{l}\text { Modelling circles } \\
\text { and coding }\end{array}$}} & \multicolumn{5}{|c|}{ K.4.1 } & \multicolumn{5}{|c|}{ K.4.2 } \\
\hline & & \multicolumn{5}{|c|}{ Sub-problems } & \multicolumn{5}{|c|}{ Sub-problems } \\
\hline & & \multirow{2}{*}{$\frac{1}{5-2}$} & \multirow{2}{*}{$\frac{2}{2-3}$} & \multirow{2}{*}{$\begin{array}{c}3 \\
3-1 \\
\end{array}$} & \multirow{2}{*}{$\begin{array}{c}\mathbf{4} \\
1-1\end{array}$} & \multirow{2}{*}{$\frac{5}{0-2}$} & \multirow{2}{*}{$\frac{1}{8-1}$} & \multirow{2}{*}{$\begin{array}{c}\mathbf{2} \\
4-1\end{array}$} & \multirow{2}{*}{$\begin{array}{c}\mathbf{3} \\
2-1\end{array}$} & \multirow{2}{*}{$\begin{array}{c}\mathbf{4} \\
3-2\end{array}$} & \multirow{2}{*}{$\begin{array}{c}\mathbf{5} \\
2-1\end{array}$} \\
\hline \multirow{5}{*}{$\mathrm{S} 1$} & $1 \mathrm{~A}$ & & & & & & & & & & \\
\hline & $1 \mathrm{~B}$ & $2-0$ & $2-1$ & $1-1$ & $1-0$ & $0-0$ & $1-2$ & $1-2$ & $0-1$ & $1-1$ & $0-1$ \\
\hline & $1 \mathrm{C}$ & $0-1$ & $1-0$ & $0-0$ & $0-0$ & $0-0$ & $0-0$ & $0-0$ & $0-0$ & $0-0$ & $0-0$ \\
\hline & $1 \mathrm{D}$ & $1-0$ & $1-1$ & $1-0$ & $0-0$ & $0-0$ & $1-1$ & $1-1$ & $1-0$ & $0-0$ & $0-0$ \\
\hline & $1 \mathrm{E}$ & $1-1$ & $1-0$ & $0-0$ & $0-0$ & $0-0$ & $0-0$ & $0-0$ & $0-0$ & $0-0$ & $0-0$ \\
\hline \multirow{3}{*}{ S2 } & $2 \mathrm{~A}$ & $0-0$ & $0-0$ & $2-0$ & $2-0$ & $0-0$ & $0-1$ & $0-0$ & $1-1$ & $1-2$ & $0-0$ \\
\hline & $2 \mathrm{~B}$ & $2-1$ & $0-4$ & $0-0$ & $5-4$ & $3-2$ & $4-1$ & $0-6$ & $0-0$ & $0-1$ & $1-0$ \\
\hline & $2 \mathrm{C}$ & $0-3$ & $1-1$ & $1-0$ & $2-0$ & $0-0$ & $1-1$ & $2-5$ & $2-0$ & $0-0$ & $0-0$ \\
\hline \multirow{3}{*}{$\mathrm{S} 3$} & $3 \mathrm{~A}$ & $10-2$ & $3-1$ & $3-0$ & $6-3$ & $1-0$ & $3-8$ & $3-6$ & $2-1$ & $2-1$ & $0-1$ \\
\hline & $3 \mathrm{~B}$ & $0-1$ & $0-0$ & $1-2$ & $3-1$ & $0-1$ & $0-0$ & $0-0$ & $0-1$ & $0-1$ & $0-1$ \\
\hline & $3 \mathrm{C}$ & $2-0$ & $2-5$ & $1-0$ & $1-1$ & $2-0$ & $1-0$ & $5-5$ & $4-1$ & $1-2$ & $1-1$ \\
\hline \multirow{2}{*}{ S4 } & $4 \mathrm{~A}$ & $0-2$ & $1-5$ & $1-1$ & $5-2$ & $0-1$ & $0-1$ & $1-4$ & $0-1$ & $2-7$ & $0-3$ \\
\hline & $4 \mathrm{~B}$ & $3-2$ & $0-8$ & $3-0$ & $1-3$ & $1-1$ & $0-3$ & $0-7$ & $0-4$ & $0-2$ & $0-2$ \\
\hline \multicolumn{2}{|c|}{ Total } & $20-21$ & $13-29$ & $17-5$ & $29-15$ & $7-7$ & $19-19$ & $17-37$ & $12-11$ & $10-19$ & 4-10 \\
\hline
\end{tabular}

For each sub-problem, the first column indicates the numbers of behaviours without the metacognitive support and the second column with the metacognitive support. 
As the Table 5 is investigated, it is noticed that K.4.1 and K.4.2 coded participants during the stage of S1 modelling period, demonstrated $1 \mathrm{~A}$ and $1 \mathrm{~B}$ coded behaviours most, It is noticed that, during the stage of S2, they demonstrated 2B coded behaviours most. During the stage of $\mathrm{S} 1$, the participants never demonstrated $1 \mathrm{C}$ and $1 \mathrm{E}$ coded behaviours in the protocols with metacognitive support. During the stage of S3, the most demonstrated behaviours by the participants are $3 \mathrm{~A}$ and followed by $3 \mathrm{C}$ coded behaviours. The most demonstrated behaviour by the participants during the stage of S4 are 4A and 4B coded behaviours and again increased in the protocols with metacognitive support.

K.4.1 and K.4.2 coded participants demonstrated totally 86-62 cognitive-metacognitive behaviours in order in the process of mathematical modelling during the stage without metacognitive support, and they demonstrated 77-96 cognitive-metacognitive behaviours in the stage with metacognitive support.

As considering the findings within the scope of the first sub-problem, those can be expressed; K.1.1, K.1.2, K.2.1, K.2.2, K.3.1, K.3.2, K.4.1 and K.4.2 coded participants, placed in the study group, demonstrated totally $56,86,7,84$, $114,122,91,62$ behaviours in order, throughout the mathematical modelling process, during the stage without metacognitive support; during the stage with metacognitive support they demonstrated totally 149, 130, 130, 116, 152, 70, 71, 96 metacognitive behaviours, in order. When the frequencies in which metacognitive support were not given to the participants subtracted from the total frequency with metacognitive support, the difference came out in 1st and 2nd grades as 93, 44, 123, 32, and in 3 rd and 4th grades as $38,-52,-20,34$.

\subsection{Findings Related to the Research Question 'Does the sequence of demonstrated cognitive-metacognitive behaviours by pre-service teachers in mathematical modelling processes vary according to the occasions with and without metacognitive support in terms of the class variable?'}

In order to find answer to this sub-problem, the findings gathered during the occasions of with and without metacognitive support are presented in order considering the class level as follows.

\subsubsection{Sequences of Cognitive-Metacognitive Behaviours of K.1.1 Coded Participant}

The findings related to the numbers of cognitive-metacognitive behaviours demonstrated by the K.1.1 coded participants within the scope of baseboard problem during the stages with and without metacognitive support are indicated in Table 6.

According to the data in Table 6, in both of the occasions in which metacognitive supports exist or not, the participant started the questions with $1 \mathrm{~A}$. In the protocols without metacognitive support, 1A behaviour was demonstrated 6 times; in the protocols with metacognitive support $1 \mathrm{~A}$ behaviour was demonstrated twice. 1B behaviour was generally demonstrated after $1 \mathrm{~A}$ and $1 \mathrm{~B}$ in the protocols with and without metacognitive support. 1C behaviour was demonstrated after $1 \mathrm{~A}$ in the protocols without metacognitive support, in the protocols with metacognitive support was demonstrated both after 1A and 4A.

While 2A behaviour did not exist in protocols without metacognitive support, in the protocols with metacognitive support, $2 \mathrm{~A}$ behaviour was demonstrated once and $2 \mathrm{~B}$ and $2 \mathrm{C}$ behaviours followed this behaviour in order. The participant demonstrated $2 \mathrm{C} 5$ times in the protocols without metacognitive support and $3 \mathrm{~A}$ followed this behaviour 21 times. For demonstration of $3 \mathrm{~B}$, a general pattern was not come out. This behaviour was demonstrated after various behaviours but generally $2 \mathrm{~B}$ and $2 \mathrm{C}$ followed this behaviour. The $3 \mathrm{C}$ behaviour was generally demonstrated after $3 \mathrm{~A}, 3 \mathrm{C}$ and $4 \mathrm{~A}$. The behaviour sequence as $2 \mathrm{~B} \rightarrow 2 \mathrm{C} \rightarrow 3 \mathrm{~A}$, during the protocols with metacognitive support, was demonstrated once during 3 th, 4 th and 5 th questions.

Table 6. Sequences of cognitive-metacognitive behaviours of $\mathrm{K} 1.1$ coded participant

\begin{tabular}{|c|c|c|}
\hline 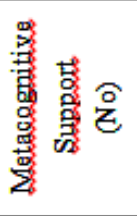 & $\begin{array}{l}\text { First Problem } \\
\text { Second Problem } \\
\text { Third Problem } \\
\text { Fourth Problem } \\
\text { Fifth Problem }\end{array}$ & $\begin{array}{l}1 \mathrm{~A} \rightarrow 1 \mathrm{~A} \rightarrow 1 \mathrm{~A} \rightarrow 1 \mathrm{~B} \rightarrow 1 \mathrm{~B} \rightarrow 2 \mathrm{~B} \rightarrow 1 \mathrm{~A} \rightarrow 1 \mathrm{~B} \rightarrow 2 \mathrm{C} \rightarrow 3 \mathrm{~A} \rightarrow 4 \mathrm{~A} \\
1 \mathrm{~A} \rightarrow 1 \mathrm{~B} \rightarrow 1 \mathrm{~B} \rightarrow 1 \mathrm{~A} \rightarrow 2 \mathrm{C} \rightarrow 3 \mathrm{~A} \rightarrow 3 \mathrm{~A} \rightarrow 1 \mathrm{~B} \rightarrow 2 \mathrm{C} \rightarrow 3 \mathrm{C} \rightarrow 3 \mathrm{C} \\
1 \mathrm{~A} \rightarrow 3 \mathrm{~B} \rightarrow 3 \mathrm{~B} \rightarrow 1 \mathrm{~B} \rightarrow 1 \mathrm{~A} \rightarrow 1 \mathrm{C} \rightarrow 2 \mathrm{C} \rightarrow 3 \mathrm{~A} \rightarrow 4 \mathrm{~A} \rightarrow 3 \mathrm{C} \\
1 \mathrm{~A} \rightarrow 1 \mathrm{~B} \rightarrow 1 \mathrm{~A} \rightarrow 1 \mathrm{C} \rightarrow 2 \mathrm{C} \rightarrow 3 \mathrm{~A} \rightarrow 3 \mathrm{~A} \rightarrow 4 \mathrm{~A}-2 \mathrm{C} \rightarrow 3 \mathrm{~A} \rightarrow 4 \mathrm{~B} \rightarrow 4 \mathrm{~A} \\
1 \mathrm{~A} \rightarrow 1 \mathrm{C} \rightarrow 3 \mathrm{~B} \rightarrow 2 \mathrm{~B} \rightarrow 2 \mathrm{C} \rightarrow 4 \mathrm{~A} \rightarrow 3 \mathrm{~A} \rightarrow 2 \mathrm{C} \rightarrow 4 \mathrm{~A} \rightarrow 3 \mathrm{C} \rightarrow 3 \mathrm{~A} \rightarrow 3 \mathrm{C}\end{array}$ \\
\hline 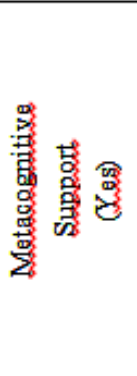 & $\begin{array}{l}\text { First Problem } \\
\text { Second Problem } \\
\text { Third Problem } \\
\text { Fourth Problem } \\
\text { Fifth Problem }\end{array}$ & $\begin{array}{l}1 \mathrm{~A} \rightarrow 1 \mathrm{~A} \rightarrow 1 \mathrm{C} \rightarrow 1 \mathrm{D} \rightarrow 1 \mathrm{~B} \rightarrow 1 \mathrm{~B} \rightarrow 1 \mathrm{~B} \rightarrow 1 \mathrm{~B} \rightarrow 2 \mathrm{~A} \rightarrow 2 \mathrm{~B} \rightarrow 2 \mathrm{~B} \rightarrow 1 \mathrm{~B} \rightarrow 2 \mathrm{C} \rightarrow 2 \mathrm{C} \rightarrow 3 \mathrm{~A} \rightarrow 4 \mathrm{~A} \rightarrow 2 \mathrm{C} \rightarrow \\
3 \mathrm{~A} \rightarrow 4 \mathrm{~A} \rightarrow 4 \mathrm{~A} \rightarrow 4 \mathrm{~A} \rightarrow 3 \mathrm{C} \rightarrow 4 \mathrm{~A} \rightarrow 1 \mathrm{~B} \rightarrow 2 \mathrm{C} \rightarrow 3 \mathrm{C} \rightarrow 2 \mathrm{C} \rightarrow 4 \mathrm{~B} \rightarrow 4 \mathrm{~B} \\
1 \mathrm{~A} \rightarrow 1 \mathrm{D} \rightarrow 2 \mathrm{~B} \rightarrow 1 \mathrm{~B} \rightarrow 2 \mathrm{C} \rightarrow 3 \mathrm{~A} \rightarrow 2 \mathrm{C} \rightarrow 3 \mathrm{~A} \rightarrow 3 \mathrm{C} \rightarrow 1 \mathrm{~B} \rightarrow 4 \mathrm{~B} \rightarrow 2 \mathrm{C} \rightarrow 3 \mathrm{~A} \rightarrow 2 \mathrm{C} \rightarrow 2 \mathrm{C} \rightarrow 3 \mathrm{~A} \rightarrow 4 \mathrm{~B} \rightarrow \\
2 \mathrm{C} \rightarrow 3 \mathrm{~A} \rightarrow 3 \mathrm{~A} \rightarrow 3 \mathrm{C} \rightarrow 3 \mathrm{C} \rightarrow 3 \mathrm{C} \rightarrow 1 \mathrm{~B} \rightarrow 3 \mathrm{~B} \rightarrow 2 \mathrm{C} \rightarrow 1 \mathrm{~B} \rightarrow 3 \mathrm{C} \rightarrow 4 \mathrm{~B} \rightarrow 2 \mathrm{~B} \rightarrow 4 \mathrm{~A}-2 \mathrm{C} \rightarrow 3 \mathrm{~A} \rightarrow 3 \mathrm{~A} \rightarrow 3 \mathrm{~A} \rightarrow \\
4 \mathrm{~B} \rightarrow 1 \mathrm{~B} \rightarrow 1 \mathrm{D} \rightarrow 2 \mathrm{~B} \rightarrow 4 \mathrm{~A} \rightarrow 1 \mathrm{~B} \rightarrow 2 \mathrm{C} \rightarrow 3 \mathrm{~A} \rightarrow 2 \mathrm{C} \rightarrow 3 \mathrm{C} \rightarrow 4 \mathrm{~A} \rightarrow 4 \mathrm{~B} \\
1 \mathrm{~A} \rightarrow 1 \mathrm{~B} \rightarrow 1 \mathrm{D} \rightarrow 2 \mathrm{C} \rightarrow 3 \mathrm{~A} \rightarrow 1 \mathrm{D} \rightarrow 4 \mathrm{~A} \rightarrow 4 \mathrm{~B} \rightarrow 4 \mathrm{~A} \rightarrow 2 \mathrm{~B} \rightarrow 2 \mathrm{C} \rightarrow 3 \mathrm{~A} \rightarrow 2 \mathrm{C} \rightarrow 3 \mathrm{~A}-2 \mathrm{C} \rightarrow 3 \mathrm{~A} \rightarrow 3 \mathrm{~A} \rightarrow 2 \mathrm{C} \rightarrow \\
3 \mathrm{C} \rightarrow 4 \mathrm{~A} \rightarrow 4 \mathrm{~B} \rightarrow 3 \mathrm{C} \rightarrow 4 \mathrm{~A} \rightarrow 4 \mathrm{~A} \rightarrow 4 \mathrm{~B} \rightarrow 4 \mathrm{~A} \\
1 \mathrm{~A} \rightarrow 1 \mathrm{~B} \rightarrow 1 \mathrm{~A} \rightarrow 2 \mathrm{~A} \rightarrow 2 \mathrm{~B} \rightarrow 2 \mathrm{C} \rightarrow 3 \mathrm{~A} \rightarrow 4 \mathrm{~B} \rightarrow 4 \mathrm{~B} \rightarrow 2 \mathrm{C} \rightarrow 3 \mathrm{~A} \rightarrow 4 \mathrm{~A} \rightarrow 3 \mathrm{~B} \rightarrow 2 \mathrm{C} \rightarrow 3 \mathrm{~A} \rightarrow 3 \mathrm{C} \rightarrow 3 \mathrm{~A} \rightarrow 4 \mathrm{~A} \rightarrow \\
3 \mathrm{~A} \rightarrow 4 \mathrm{~A} \rightarrow 2 \mathrm{C} \rightarrow 3 \mathrm{~A} \rightarrow 4 \mathrm{~A} \rightarrow 3 \mathrm{C} \rightarrow 3 \mathrm{C} \rightarrow 4 \mathrm{~A} \rightarrow 1 \mathrm{C} \rightarrow 4 \mathrm{~B} \\
1 \mathrm{~A} \rightarrow 2 \mathrm{~B} \rightarrow 3 \mathrm{~B} \rightarrow 2 \mathrm{~B} \rightarrow 2 \mathrm{C} \rightarrow 3 \mathrm{~A} \rightarrow 2 \mathrm{C} \rightarrow 3 \mathrm{~A} \rightarrow 2 \mathrm{C} \rightarrow 3 \mathrm{~A} \rightarrow 3 \mathrm{~A} \rightarrow 4 \mathrm{~B}-2 \mathrm{C} \rightarrow 3 \mathrm{~A} \rightarrow 4 \mathrm{~A} \rightarrow 1 \mathrm{~B} \rightarrow 4 \mathrm{~A} \rightarrow 4 \mathrm{~A} \rightarrow \\
4 \mathrm{~B}\end{array}$ \\
\hline
\end{tabular}


The participant finished all the questions with $4 \mathrm{~A}$ or $4 \mathrm{~B}$ during the protocols with metacognitive support. During the protocols without metacognitive support, the participants demonstrated only one behaviour within the scope of $4 \mathrm{~B}$ and this behaviour was followed by $4 \mathrm{~A}$. The demonstration of the $4 \mathrm{~A}$ and $4 \mathrm{~B}$ behaviours during the protocols with metacognitive support was more than the demonstration of the behaviours without metacognitive support. $4 \mathrm{~A}$ behaviour was demonstrated after $3 \mathrm{~A}$ most during the protocols without ( 3 times) and with metacognitive support (7 times).

\subsubsection{Sequences of Cognitive-Metacognitive Behaviours of K.1.2 Coded Participant}

The findings related to the numbers of cognitive-metacognitive behaviours demonstrated by the K.1.2 coded participants within the scope of baseboard problem during the stages with and without metacognitive support are indicated in Table 7.

According to the data in Table 7, in both of the occasions in which metacognitive support exists or not, the participant started the questions with $1 \mathrm{~A}$. The $1 \mathrm{~A}$ behaviour was demonstrated 4 times after cognitive-metacognitive behaviour during the protocols with and without metacognitive support. 1B behaviour was generally demonstrated after 1A, 1B and 1D behaviours during the protocols without and with metacognitive support. This participant in none of the two stages never demonstrated $1 \mathrm{C}$ and $1 \mathrm{E}$ behaviours.

During the protocols without metacognitive support of the participant, $3 \mathrm{~A}$ behaviour followed $2 \mathrm{C} 12$ times and 12 times during the protocols with metacognitive support. While 3B behaviour was demonstrated only once during the protocols without metacognitive support, it was demonstrated several times after various behaviours during the protocols with metacognitive support. And $3 \mathrm{C}$ behaviour followed $3 \mathrm{~A}$ several times. The behaviour sequences as $2 \mathrm{~B} \rightarrow 2 \mathrm{C} \rightarrow 3 \mathrm{~A}$ were demonstrated twice during the second question during the protocols without metacognitive support, and once in 4th and 5th questions. This behaviour sequences were demonstrated once in second question during the protocols with metacognitive support.

During the stage without metacognitive support, the participant finished the problem solving processes with 3C 5 times, in the occasions with metacognitive support finished the processes twice with $4 \mathrm{~A}$, twice with $4 \mathrm{~B}$ and once with $1 \mathrm{~B}$. There is no behaviour which can be evaluated within the scope of $4 \mathrm{~B}$ code was demonstrated by the participant during the protocols without metacognitive support. The 4A behaviour was demonstrated after $3 \mathrm{~A}$ most (5 times) during the protocols without metacognitive support, and it was demonstrated after $4 \mathrm{~A}$ most (4 times) during the protocols with metacognitive support.

Table 7. Sequences of cognitive-metacognitive behaviours of K 1.2 coded participant

\begin{tabular}{|c|c|c|}
\hline 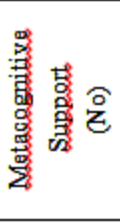 & $\begin{array}{l}\text { First Problem } \\
\text { Second Problem } \\
\text { Third Problem } \\
\text { Fourth Problem } \\
\text { Fifth Problem }\end{array}$ & $\begin{array}{l}1 \mathrm{~A} \rightarrow 1 \mathrm{D} \rightarrow 1 \mathrm{~A} \rightarrow 1 \mathrm{D} \rightarrow 1 \mathrm{~B} \rightarrow 1 \mathrm{~A} \rightarrow 1 \mathrm{~A} \rightarrow 1 \mathrm{~B} \rightarrow 2 \mathrm{C} \rightarrow 3 \mathrm{~A} \rightarrow 2 \mathrm{C} \rightarrow 3 \mathrm{C} \rightarrow 3 \mathrm{C} \rightarrow 3 \mathrm{C} \rightarrow 3 \mathrm{~B} \rightarrow 2 \mathrm{C} \rightarrow 3 \mathrm{C} \\
1 \mathrm{~A} \rightarrow 1 \mathrm{~B} \rightarrow 2 \mathrm{~A} \rightarrow 1 \mathrm{D} \rightarrow 2 \mathrm{~B} \rightarrow 2 \mathrm{C} \rightarrow 3 \mathrm{~A} \rightarrow 2 \mathrm{C} \rightarrow 2 \mathrm{C} \rightarrow 2 \mathrm{~B} \rightarrow 2 \mathrm{C} \rightarrow 3 \mathrm{~A} \rightarrow 4 \mathrm{~A} \rightarrow 2 \mathrm{C} \rightarrow 2 \mathrm{C} \rightarrow 2 \mathrm{~A} \rightarrow 3 \mathrm{C} \rightarrow \\
3 \mathrm{~A} \rightarrow 3 \mathrm{C} \rightarrow 3 \mathrm{C} \\
1 \mathrm{~A} \rightarrow 1 \mathrm{D} \rightarrow 1 \mathrm{~B} \rightarrow 1 \mathrm{E} \rightarrow 2 \mathrm{~A} \rightarrow 4 \mathrm{~A} \rightarrow 2 \mathrm{C} \rightarrow 3 \mathrm{~A} \rightarrow 2 \mathrm{C} \rightarrow 3 \mathrm{~A} \rightarrow 4 \mathrm{~A}-2 \mathrm{C} \rightarrow 3 \mathrm{~A} \rightarrow, 1 \mathrm{~A} \rightarrow 3 \mathrm{C} \\
1 \mathrm{~A} \rightarrow 1 \mathrm{D} \rightarrow 1 \mathrm{~B} \rightarrow 3 \mathrm{~A} \rightarrow 2 \mathrm{~B} \rightarrow 2 \mathrm{C} \rightarrow 3 \mathrm{~A} \rightarrow 2 \mathrm{C} \rightarrow 3 \mathrm{~A}+2 \mathrm{C} \rightarrow 3 \mathrm{~A} \rightarrow 4 \mathrm{~A} \rightarrow 3 \mathrm{~A} \rightarrow 3 \mathrm{~A} \rightarrow 1 \mathrm{~A} \rightarrow 3 \mathrm{C} \\
1 \mathrm{~A} \rightarrow 1 \mathrm{D} \rightarrow 2 \mathrm{~B} \rightarrow 2 \mathrm{~B} \rightarrow 2 \mathrm{C} \rightarrow 3 \mathrm{~A} \rightarrow 2 \mathrm{C}-3 \mathrm{~A} \rightarrow 4 \mathrm{~A} \rightarrow 3 \mathrm{C} \rightarrow 3 \mathrm{~A} \rightarrow 2 \mathrm{~B} \rightarrow 3 \mathrm{~A} \rightarrow 2 \mathrm{C} \rightarrow 3 \mathrm{~A} \rightarrow 4 \mathrm{~A} \rightarrow 3 \mathrm{C} \rightarrow 3 \mathrm{C}\end{array}$ \\
\hline 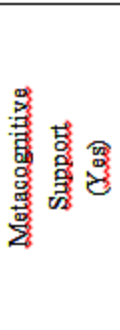 & $\begin{array}{l}\text { Second Problem } \\
\text { Third Problem } \\
\text { Eourth Problem } \\
\text { Eifth Problem }\end{array}$ & $\begin{array}{l}1 \mathrm{~A} \rightarrow 1 \mathrm{~B} \rightarrow 1 \mathrm{~A} \rightarrow 1 \mathrm{~B} \rightarrow 2 \mathrm{~B} \rightarrow 3 \mathrm{~B} \rightarrow 4 \mathrm{~B} \rightarrow 4 \mathrm{~B} \rightarrow 4 \mathrm{~B} \rightarrow 3 \mathrm{~B} \rightarrow 4 \mathrm{~B} \rightarrow 2 \mathrm{C} \rightarrow 3 \mathrm{~A} \rightarrow 3 \mathrm{C} \rightarrow 1 \mathrm{D} \rightarrow 1 \mathrm{~B} \rightarrow 2 \mathrm{C} \rightarrow 1 \mathrm{~B} \rightarrow \\
2 \mathrm{C} \rightarrow 2 \mathrm{~A} \rightarrow 3 \mathrm{~B} \rightarrow 4 \mathrm{~B} \rightarrow 2 \mathrm{C} \rightarrow 4 \mathrm{~B} \rightarrow 1 \mathrm{~B} \rightarrow 3 \mathrm{C} \rightarrow 4 \mathrm{~B} \rightarrow 1 \mathrm{~B} \rightarrow 1 \mathrm{~A} \rightarrow 1 \mathrm{~B} \rightarrow 4 \mathrm{~B} \rightarrow 3 \mathrm{~B} \rightarrow 3 \mathrm{C} \rightarrow 3 \mathrm{~B} \rightarrow 3 \mathrm{C} \rightarrow 3 \mathrm{C} \rightarrow \\
4 \mathrm{~B} \rightarrow 1 \mathrm{~B} \\
1 \mathrm{~A} \rightarrow 1 \mathrm{~A} \rightarrow 1 \mathrm{~B} \rightarrow 2 \mathrm{~A} \rightarrow 2 \mathrm{~B} \rightarrow 1 \mathrm{D}-2 \mathrm{C} \rightarrow 3 \mathrm{~A} \rightarrow 3 \mathrm{~A} \rightarrow 2 \mathrm{C} \rightarrow 2 \mathrm{~A} \rightarrow 2 \mathrm{C} \rightarrow 3 \mathrm{~A} \rightarrow 3 \mathrm{C} \rightarrow 4 \mathrm{~B} \rightarrow 3 \mathrm{~B} \rightarrow 3 \mathrm{~B} \rightarrow 3 \mathrm{~A} \rightarrow \\
3 \mathrm{~A} \rightarrow 4 \mathrm{~B} \rightarrow 1 \mathrm{D} \rightarrow 4 \mathrm{~B} \rightarrow 4 \mathrm{~B} \rightarrow 2 \mathrm{C} \rightarrow 3 \mathrm{C} \rightarrow 3 \mathrm{C} \rightarrow 2 \mathrm{~B}-2 \mathrm{C} \rightarrow 3 \mathrm{~A} \rightarrow 1 \mathrm{~B} \rightarrow 4 \mathrm{~A} \rightarrow 4 \mathrm{~A} \rightarrow 4 \mathrm{~B} \\
1 \mathrm{~A} \rightarrow 1 \mathrm{~B} \rightarrow 1 \mathrm{~B} \rightarrow 2 \mathrm{~A} \rightarrow 1 \mathrm{~B} \rightarrow 2 \mathrm{~B} \rightarrow 3 \mathrm{~A} \rightarrow 2 \mathrm{~B} \rightarrow 3 \mathrm{~A} \rightarrow 2 \mathrm{C} \rightarrow 3 \mathrm{~B} \rightarrow 2 \mathrm{C} \rightarrow 3 \mathrm{~A} \rightarrow 2 \mathrm{C} \rightarrow 3 \mathrm{~A} \rightarrow 2 \mathrm{C} \rightarrow 3 \mathrm{~A} \rightarrow 3 \mathrm{C} \rightarrow \\
4 \mathrm{~A} \rightarrow 2 \mathrm{C} \rightarrow 3 \mathrm{~A} \rightarrow 4 \mathrm{~A} \rightarrow 4 \mathrm{~B} \\
1 \mathrm{~A} \rightarrow 1 \mathrm{~A} \rightarrow 3 \mathrm{~B} \rightarrow 2 \mathrm{~A} \rightarrow 1 \mathrm{~B} \rightarrow 2 \mathrm{C} \rightarrow 3 \mathrm{~B} \rightarrow 3 \mathrm{~A} \rightarrow 4 \mathrm{~A} \rightarrow 4 \mathrm{~A} \rightarrow 4 \mathrm{~A} \rightarrow 4 \mathrm{~A} \rightarrow \\
1 \mathrm{~A} \rightarrow 1 \mathrm{~B} \rightarrow 1 \mathrm{~B} \rightarrow 2 \mathrm{~B} \rightarrow 4 \mathrm{~A} \rightarrow 2 \mathrm{~B} \rightarrow 1 \mathrm{~B} \rightarrow 1 \mathrm{D} \rightarrow 2 \mathrm{C} \rightarrow 3 \mathrm{~A} \rightarrow 3 \mathrm{~A} \rightarrow 2 \mathrm{C} \rightarrow 3 \mathrm{~A} \rightarrow 2 \mathrm{C} \rightarrow 3 \mathrm{~A} \rightarrow 2 \mathrm{C} \rightarrow 3 \mathrm{~A} \rightarrow 2 \mathrm{C} \rightarrow \\
1 \mathrm{E} \rightarrow 3 \mathrm{C} \rightarrow 3 \mathrm{~A} \rightarrow 3 \mathrm{~A} \rightarrow 4 \mathrm{~B} \rightarrow 4 \mathrm{~A}\end{array}$ \\
\hline
\end{tabular}


Table 8. Sequences of cognitive-metacognitive behaviours of K 2.1 coded participant

\begin{tabular}{|c|c|c|}
\hline 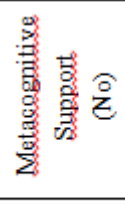 & $\begin{array}{l}\text { First Problem } \\
\text { Second Problem } \\
\text { Third Problem } \\
\text { Eourth Problem } \\
\text { Eifth Problem }\end{array}$ & $\begin{array}{l}1 \mathrm{~A} \rightarrow 1 \mathrm{D} \rightarrow 2 \mathrm{~A} \rightarrow 1 \mathrm{E} \rightarrow 1 \mathrm{~A} \\
1 \mathrm{~A} \\
1 \mathrm{~A}\end{array}$ \\
\hline 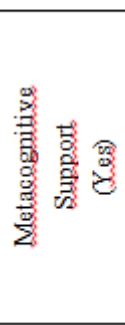 & $\begin{array}{l}\text { First Problem } \\
\text { Second Problem } \\
\text { Third Problem } \\
\text { Eourth Problem } \\
\text { EifthProblem }\end{array}$ & $\begin{array}{l}1 \mathrm{~A} \rightarrow 1 \mathrm{D} \rightarrow 1 \mathrm{~B} \rightarrow 2 \mathrm{~A} \rightarrow 1 \mathrm{~B} \rightarrow 2 \mathrm{~A} \rightarrow 1 \mathrm{~B} \rightarrow 3 \mathrm{~A} \rightarrow 2 \mathrm{C} \rightarrow 2 \mathrm{~A}-2 \mathrm{C} \rightarrow 3 \mathrm{~A} \rightarrow 2 \mathrm{C} \rightarrow 1 \mathrm{~B} \rightarrow 1 \mathrm{~B} \rightarrow 2 \mathrm{C} \rightarrow 3 \mathrm{~A} \rightarrow 3 \mathrm{~B} \rightarrow \\
3 \mathrm{~A} \rightarrow 4 \mathrm{~A} \rightarrow 4 \mathrm{~B} \rightarrow 2 \mathrm{C} \rightarrow 3 \mathrm{~A} \rightarrow 2 \mathrm{C} \rightarrow 3 \mathrm{~A} \rightarrow 4 \mathrm{~A} \rightarrow 4 \mathrm{~A} \rightarrow 1 \mathrm{~B} \rightarrow 4 \mathrm{~B} \rightarrow 4 \mathrm{~B} \rightarrow 2 \mathrm{C} \rightarrow 3 \mathrm{~A} \rightarrow 3 \mathrm{~A} \rightarrow 1 \mathrm{~B} \rightarrow 2 \mathrm{C} \rightarrow 3 \mathrm{~A} \rightarrow \\
2 \mathrm{C} \rightarrow 3 \mathrm{~A} \rightarrow 2 \mathrm{C} \rightarrow 3 \mathrm{~A} \rightarrow 2 \mathrm{C} \rightarrow 3 \mathrm{~A} \rightarrow 4 \mathrm{~A} \rightarrow 4 \mathrm{~B} \\
1 \mathrm{~B} \rightarrow 1 \mathrm{~A} \rightarrow 1 \mathrm{~B} \rightarrow 1 \mathrm{~B} \rightarrow 2 \mathrm{~B} \rightarrow 2 \mathrm{C} \rightarrow 3 \mathrm{~A} \rightarrow 2 \mathrm{C} \rightarrow 2 \mathrm{~B} \rightarrow 1 \mathrm{~A}-2 \mathrm{~B} \rightarrow 2 \mathrm{C} \rightarrow 3 \mathrm{~A} \rightarrow 3 \mathrm{~A} \rightarrow 2 \mathrm{~B} \rightarrow 2 \mathrm{C} \rightarrow 3 \mathrm{~A} \rightarrow 1 \mathrm{~A} \rightarrow \\
1 \mathrm{~A} \rightarrow 3 \mathrm{C} \rightarrow 3 \mathrm{C} \rightarrow 3 \mathrm{C} \rightarrow 4 \mathrm{~B} \rightarrow 4 \mathrm{~A} \\
1 \mathrm{~A} \rightarrow 1 \mathrm{~A} \rightarrow 1 \mathrm{D} \rightarrow 1 \mathrm{~B} \rightarrow 3 \mathrm{~B} \rightarrow 3 \mathrm{C} \rightarrow 4 \mathrm{~B} \rightarrow 4 \mathrm{~B} \rightarrow 2 \mathrm{C} \rightarrow 3 \mathrm{~A} \rightarrow 2 \mathrm{C} \rightarrow 3 \mathrm{~A} \rightarrow 4 \mathrm{~A} \rightarrow 4 \mathrm{~B} \rightarrow 4 \mathrm{~A} \\
1 \mathrm{~A} \rightarrow 1 \mathrm{D} \rightarrow 1 \mathrm{~A} \rightarrow 1 \mathrm{~B} \rightarrow 2 \mathrm{~B}-2 \mathrm{C} \rightarrow 3 \mathrm{~A}) \rightarrow 2 \mathrm{C} \rightarrow 3 \mathrm{~A} \rightarrow 3 \mathrm{~B} \rightarrow 2 \mathrm{C} \rightarrow 3 \mathrm{~A} \rightarrow 2 \mathrm{C} \rightarrow 4 \mathrm{~A} \rightarrow 3 \mathrm{~A} \rightarrow 2 \mathrm{C} \rightarrow 3 \mathrm{~A} \rightarrow 4 \mathrm{~A} \\
2 \mathrm{C} \rightarrow 3 \mathrm{~A} \rightarrow 4 \mathrm{~A} \rightarrow 4 \mathrm{~A} \rightarrow 3 \mathrm{C} \rightarrow 4 \mathrm{~B} \\
1 \mathrm{~A} \rightarrow 1 \mathrm{D} \rightarrow 1 \mathrm{~A} \rightarrow 3 \mathrm{~B} \rightarrow 2 \mathrm{~B} \rightarrow 2 \mathrm{~A} \rightarrow 2 \mathrm{C} \rightarrow 1 \mathrm{~B} \rightarrow 2 \mathrm{C} \rightarrow 3 \mathrm{~A} \rightarrow 3 \mathrm{~B} \rightarrow 2 \mathrm{~B} \rightarrow 2 \mathrm{C} \rightarrow 3 \mathrm{~A} \rightarrow 4 \mathrm{~A} \rightarrow 3 \mathrm{~A} \rightarrow \\
2 \mathrm{C} \rightarrow 3 \mathrm{~A} \rightarrow 4 \mathrm{~A} \rightarrow 2 \mathrm{C} \rightarrow 2 \mathrm{C} \rightarrow 4 \mathrm{~A} \rightarrow 4 \mathrm{~A}\end{array}$ \\
\hline
\end{tabular}

Table 9. Sequences of cognitive-metacognitive behaviours of $\mathrm{K} 2.2$ coded participant

\begin{tabular}{|c|c|c|}
\hline \multirow{5}{*}{ 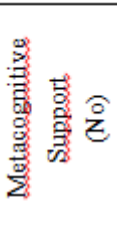 } & $m$ & $\begin{array}{l}1 \mathrm{~A} \rightarrow 1 \mathrm{~B} \rightarrow 1 \mathrm{D} \rightarrow 1 \mathrm{~B} \rightarrow 2 \mathrm{~B} \rightarrow 1 \mathrm{D} \rightarrow 1 \mathrm{E} \rightarrow 1 \mathrm{~A} \rightarrow 2 \mathrm{C} \rightarrow 1 \mathrm{~B} \rightarrow 1 \mathrm{~A} \rightarrow 2 \mathrm{~B} \rightarrow 2 \mathrm{C} \rightarrow 3 \mathrm{~A} \rightarrow 3 \mathrm{C} \rightarrow 1 \mathrm{~B} \rightarrow 1 \mathrm{~A} \rightarrow 1 \mathrm{~A} \rightarrow \\
1 \mathrm{~A} \rightarrow 1 \mathrm{~B} \rightarrow 2 \mathrm{C} \rightarrow 2 \mathrm{~B} \rightarrow 1 \mathrm{E} \rightarrow 1 \mathrm{D} \rightarrow 2 \mathrm{C} \rightarrow 2 \mathrm{~B} \rightarrow 3 \mathrm{~A} \rightarrow 2 \mathrm{C} \rightarrow 3 \mathrm{C} \rightarrow 4 \mathrm{~B} \rightarrow 2 \mathrm{~B} \rightarrow 3 \mathrm{C} \rightarrow 3 \mathrm{C} \rightarrow 3 \mathrm{C} \rightarrow 4 \mathrm{~B}\end{array}$ \\
\hline & & $1 \mathrm{~A} \rightarrow 1 \mathrm{~B} \rightarrow 2 \mathrm{~A} \rightarrow 1 \mathrm{D} \rightarrow 3 \mathrm{~A} \rightarrow 2 \mathrm{C} \rightarrow 2 \mathrm{C} \rightarrow 3 \mathrm{C} \rightarrow 3 \mathrm{C}$ \\
\hline & & $1 \mathrm{~A} \rightarrow 1 \mathrm{C} \rightarrow 1 \mathrm{C} \rightarrow 1 \mathrm{C} \rightarrow 1 \mathrm{C} \rightarrow 1 \mathrm{D} \rightarrow 2 \mathrm{C} \rightarrow 4 \mathrm{~B} \rightarrow 2 \mathrm{C} \rightarrow 3 \mathrm{~A} \rightarrow 2 \mathrm{C} \rightarrow 3 \mathrm{~A} \rightarrow 4 \mathrm{~A} \rightarrow 3 \mathrm{C}$ \\
\hline & & $1 \mathrm{~A} \rightarrow 1 \mathrm{~A} \rightarrow 1 \mathrm{D} \rightarrow 1 \mathrm{~B} \rightarrow 2 \mathrm{~B} \rightarrow 3 \mathrm{~A} \rightarrow 2 \mathrm{C} \rightarrow 2 \mathrm{C} \rightarrow 3 \mathrm{~A} \rightarrow 2 \mathrm{~B} \rightarrow 3 \mathrm{C} \rightarrow 3 \mathrm{~A}$ \\
\hline & & $1 \mathrm{~A} \rightarrow 1 \mathrm{C} \rightarrow 1 \mathrm{~B} \rightarrow 1 \mathrm{C} \rightarrow 1 \mathrm{~A} \rightarrow 1 \mathrm{~A} \rightarrow 1 \mathrm{C} \rightarrow 1 \mathrm{D} \rightarrow 2 \mathrm{~A} \rightarrow 2 \mathrm{~B} \rightarrow 2 \mathrm{C} \rightarrow 2 \mathrm{~A} \rightarrow 1 \mathrm{~B} \rightarrow 3 \mathrm{C}$ \\
\hline \multirow{5}{*}{ 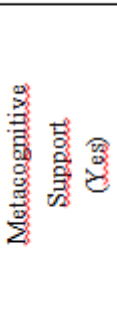 } & Prob & $\begin{array}{l}1 \mathrm{~A} \rightarrow 1 \mathrm{~B} \rightarrow 1 \mathrm{~B} \rightarrow 1 \mathrm{~B} \rightarrow 1 \mathrm{~B} \rightarrow 1 \mathrm{C} \rightarrow 2 \mathrm{~B} \rightarrow 2 \mathrm{~B} \rightarrow 2 \mathrm{~A} \rightarrow 3 \mathrm{~A} \rightarrow 2 \mathrm{~B} \rightarrow 3 \mathrm{~A} \rightarrow 2 \mathrm{C} \rightarrow 3 \mathrm{C} \rightarrow 4 \mathrm{~A} \rightarrow 4 \mathrm{~B}-2 \mathrm{~B} \rightarrow 3 \mathrm{~A} \rightarrow \\
2 \mathrm{C} \rightarrow 3 \mathrm{C} \rightarrow 4 \mathrm{~B} \rightarrow 2 \mathrm{~B} \rightarrow 3 \mathrm{C} \rightarrow 4 \mathrm{~B} \rightarrow 3 \mathrm{C} \rightarrow 3 \mathrm{C} \rightarrow 4 \mathrm{~A} \rightarrow 2 \mathrm{~B} \rightarrow 2 \mathrm{~A} \rightarrow 2 \mathrm{~B} \rightarrow 4 \mathrm{~A} \rightarrow 3 \mathrm{~A} \rightarrow 3 \mathrm{~A} \rightarrow 3 \mathrm{~A} \rightarrow 3 \mathrm{~A} \rightarrow 3 \mathrm{~A} \rightarrow \\
3 \mathrm{~A} \rightarrow 3 \mathrm{~A}-3 \mathrm{~A} \rightarrow 4 \mathrm{~A}\end{array}$ \\
\hline & Second Problem & $1 \mathrm{~A} \rightarrow 1 \mathrm{~B} \rightarrow 2 \mathrm{~A} \rightarrow 2 \mathrm{C} \rightarrow 4 \mathrm{~A} \rightarrow 2 \mathrm{C} \rightarrow 3 \mathrm{~A} \rightarrow 3 \mathrm{C} \rightarrow 2 \mathrm{C} \rightarrow 3 \mathrm{~A} \rightarrow 2 \mathrm{C} \rightarrow 3 \mathrm{C} \rightarrow 3 \mathrm{C} \rightarrow 3 \mathrm{C} \rightarrow 1 \mathrm{~B} \rightarrow 4 \mathrm{~B} \rightarrow 4 \mathrm{~B} \rightarrow 4 \mathrm{~A}$ \\
\hline & Third Problem & $\begin{array}{l}1 \mathrm{~A} \rightarrow 1 \mathrm{~B} \rightarrow 1 \mathrm{D}-2 \mathrm{C} \rightarrow 3 \mathrm{~A} \rightarrow 3 \mathrm{C}-2 \mathrm{C} \rightarrow 3 \mathrm{~A} \rightarrow 3 \mathrm{C} \rightarrow 3 \mathrm{C} \rightarrow 4 \mathrm{~B} \rightarrow 3 \mathrm{~B} \rightarrow 2 \mathrm{C} \rightarrow 1 \mathrm{~B}-2 \mathrm{C} \rightarrow 3 \mathrm{~A}-2 \mathrm{C} \rightarrow 3 \mathrm{~A} \rightarrow \\
2 \mathrm{C} \rightarrow 3 \mathrm{~A} \rightarrow 4 \mathrm{~B} \rightarrow 2 \mathrm{C} \rightarrow 3 \mathrm{~A} \rightarrow 3 \mathrm{C} \rightarrow 4 \mathrm{~B} \rightarrow 3 \mathrm{~A} \rightarrow 3 \mathrm{~B} \rightarrow 4 \mathrm{~A} \rightarrow 4 \mathrm{~B}\end{array}$ \\
\hline & Fourth Problem & $\begin{array}{l}1 \mathrm{~A} \rightarrow 1 \mathrm{~B} \rightarrow 2 \mathrm{~B} \rightarrow 2 \mathrm{~B} \rightarrow 1 \mathrm{~B} \rightarrow 2 \mathrm{~B} \rightarrow 3 \mathrm{~A} \rightarrow 2 \mathrm{C} \rightarrow 3 \mathrm{~A} \rightarrow 4 \mathrm{~A}-2 \mathrm{C} \rightarrow 3 \mathrm{~A} \rightarrow 3 \mathrm{~B} \rightarrow 2 \mathrm{C} \rightarrow 3 \mathrm{~A} \rightarrow 4 \mathrm{~A} \rightarrow 3 \mathrm{C} \rightarrow 4 \mathrm{~B} \rightarrow \\
4 \mathrm{~A} \rightarrow 3 \mathrm{C} \rightarrow 4 \mathrm{~A}\end{array}$ \\
\hline & Eifth Problem & $1 \mathrm{~A} \rightarrow 1 \mathrm{~A} \rightarrow 2 \mathrm{~B} \rightarrow 2 \mathrm{~B} \rightarrow 2 \mathrm{C} \rightarrow 3 \mathrm{~A} \rightarrow 4 \mathrm{~B} \rightarrow 3 \mathrm{C}$ \\
\hline
\end{tabular}

\subsubsection{Sequences of Cognitive-Metacognitive Behaviours of} K.2.1 Coded Participant

The findings related to the numbers of cognitive-metacognitive behaviours demonstrated by the K.2.1 coded participants within the scope of baseboard problem during the stages with and without metacognitive support are indicated in Table 8.

According to the data in Table 8, the participant finished the process thinking that he cannot solve the problems without metacognitive support. The participant, during the occasion with metacognitive support, demonstrated behaviours within the scope of all of the codes except for $1 \mathrm{C}$ and 1E. Problem solving process started with 1A.During the protocols without metacognitive support, the $1 \mathrm{~A}$ behaviour was demonstrated once after cognitive-metacognitive behaviour, and during the protocols with metacognitive support 6 times. The participant demonstrated 1B coded behaviour in all of the solving processes intensively except for the 4th and 5th questions during the protocols with metacognitive support.

The participant demonstrated $2 \mathrm{C}$ behaviour 22 times before $3 \mathrm{~A}$ behaviour, however, in second, fourth and fifth questions, he demonstrated $2 \mathrm{C}$ after $2 \mathrm{~B}$, and $3 \mathrm{~A}$ after $2 \mathrm{C}$. The behaviour $3 \mathrm{~B}$ was usually demonstrated after $3 \mathrm{~A}$. Furthermore, the participant demonstrated $3 \mathrm{C}$ behaviour quite a few times, and during some solving processes, he did not demonstrate it at all. The behaviour sequences as $2 \mathrm{~B} \rightarrow$ $2 \mathrm{C} \rightarrow 3 \mathrm{~A}$ were demonstrated by the participant during the protocols with metacognitive support, 3 times in second question and once in 4th and 5th questions.

The participant finished the problem solving processes with $4 \mathrm{~A}$ three times and with $4 \mathrm{~B}$ twice. The $4 \mathrm{~A}$ and $4 \mathrm{~B}$ coded behaviours were demonstrated not only at the end of the problem solving process but also in the middle of the process and mostly after each other. During the protocols with metacognitive support, the behaviour $4 \mathrm{~A}$ was demonstrated after $3 \mathrm{~A}$ most (8 times).

\subsubsection{Sequences of Cognitive-Metacognitive Behaviours of K.2.2 Coded Participant}

The findings related to the numbers of cognitive-metacognitive behaviours demonstrated by the K.2.2 coded participants within the scope of baseboard problem during the stages with and without metacognitive support are indicated in Table 9.

According to the data in Table 9, the participant in each situation, started all of the problem solving process with $1 \mathrm{~A}$. $1 \mathrm{~A}$ behaviour was demonstrated 6 times after the cognitive-metacognitive behaviour during the protocols without metacognitive support, and once during the 
protocols with metacognitive support. The participant demonstrated $1 \mathrm{C}$ in all of the solving processes intensively in the occasion without metacognitive support but he demonstrated the behaviour only once during the stage with metacognitive support.

During the protocols without metacognitive support, $3 \mathrm{~A}$ followed 2C 4 times, and during the protocols with metacognitive support 12 times. Moreover, 3A followed 2B 3 times during the protocols with metacognitive support. While 3B behaviour did not take place during the protocols without metacognitive support, it was demonstrated twice after $3 \mathrm{~A}$ and once after 4B. 3C behaviour was demonstrated after $3 \mathrm{~A}$ and $3 \mathrm{C}$ behaviour most. The behaviour sequence as $2 \mathrm{~B} \rightarrow 2 \mathrm{C} \rightarrow 3 \mathrm{~A}$ was demonstrated once in the 1 st question during the protocols without metacognitive support, and once in the 5th question with metacognitive support.

While the participant finished the problem solving processes 3 times with $3 \mathrm{C}$ and once with $3 \mathrm{~A}$ and once with $4 \mathrm{~B}$ during the stage without metacognitive support, he finished the processes 3 times with $4 \mathrm{~A}$, once with $4 \mathrm{~B}$ and once with $3 \mathrm{C}$ during the stage with metacognitive support. During the protocols without metacognitive support, 4A was demonstrated once and before it $3 \mathrm{~A}$ was demonstrated. During the protocols with metacognitive support, 4A behaviour was demonstrated most (3 times) after $3 \mathrm{~A}$ behaviour.

\subsubsection{Sequences of Cognitive-Metacognitive Behaviours of} K.3.1 Coded Participant

The findings related to the numbers of cognitive-metacognitive behaviours demonstrated by the K.3.1 coded participants within the scope of baseboard problem during the stages with and without metacognitive support are indicated in Table 10.

According to the data in Table 10, the participant, except for the third question in the stage with metacognitive support, started the problem solving process with 1A. During the protocols without metacognitive support, 1A behaviour was demonstrated 3 times after a cognitive -metacognitive behaviour, but during the protocols with metacognitive support, this demonstration was 6 times.

During the protocols without metacognitive support of the participant, 3A behaviour followed 2C 12 times, and 6 times during the protocols with metacognitive support. Moreover, during the protocols without metacognitive support of the participant, 3A behaviour followed $2 \mathrm{~B}$ once, during the protocols with metacognitive support 8 times. 3C behaviour was demonstrated after $3 \mathrm{~A}$ and $3 \mathrm{C}$ both during the protocols with and without metacognitive support. The behaviour sequences as $2 \mathrm{~B} \rightarrow 2 \mathrm{C} \rightarrow 3 \mathrm{~A}$ were demonstrated 3 times in the 3 rd question during the protocols without metacognitive support and twice in the 3rd question during the protocols with metacognitive support.

While the participant finished the problem solving process with 3C five times during the protocols without metacognitive support, 3 times with $4 \mathrm{~B}$, once with $4 \mathrm{~A}$ and once with $1 \mathrm{~B}$ during the protocols with metacognitive support. Moreover, during the protocols with metacognitive support, 4A and 4B coded behaviours were demonstrated in second, third and fourth questions intensively. During the protocols without metacognitive support, 4A behaviour was demonstrated after $2 \mathrm{C}$ most (5 times), during the protocols with metacognitive support it was demonstrated after $3 \mathrm{C}$ most (6 times).

Table 10. Sequences of cognitive-metacognitive behaviours of $K 3.1$ coded participant

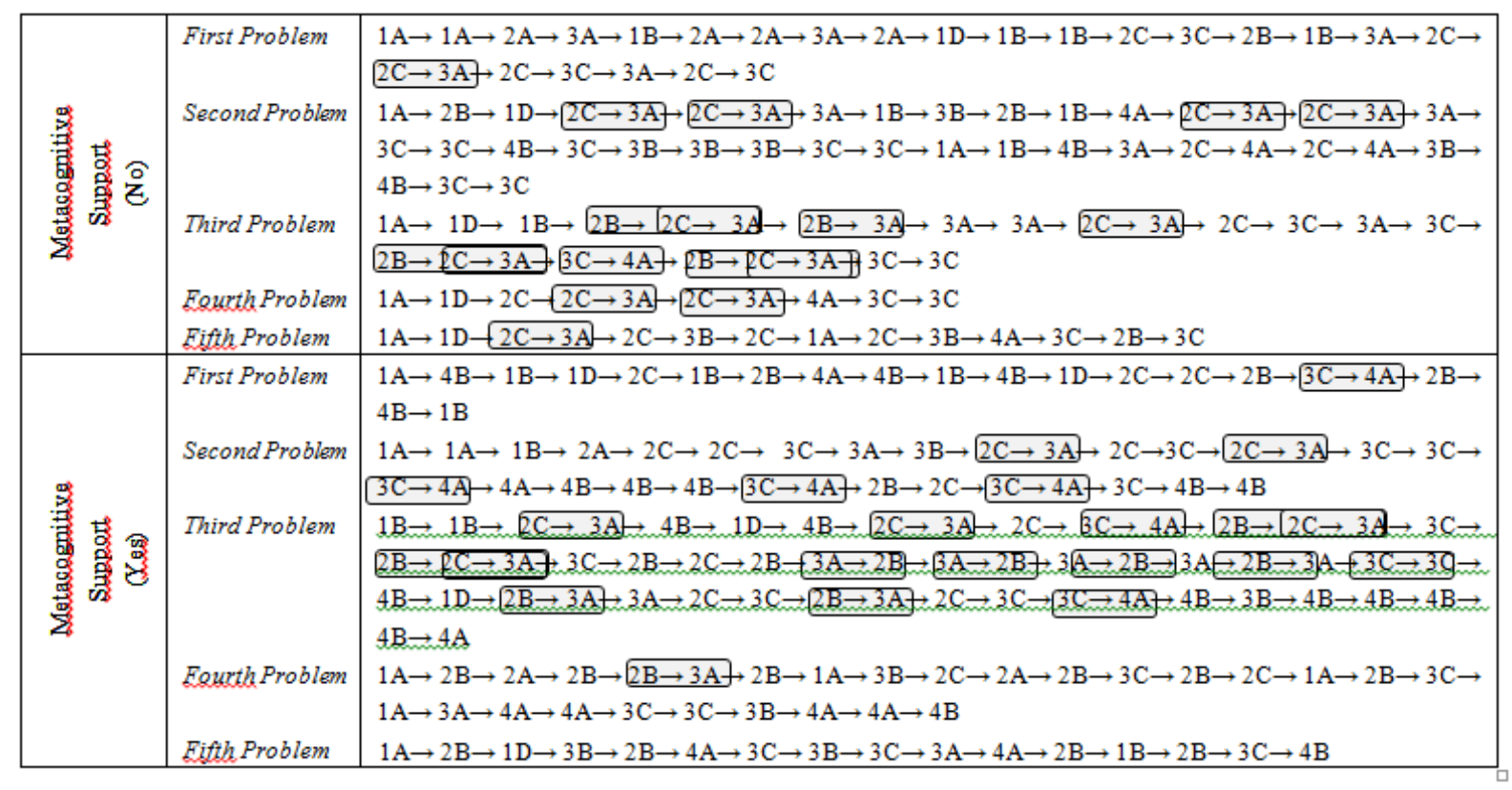


Table 11. Sequences of cognitive-metacognitive behaviours of K 3.2 coded participant

\begin{tabular}{|c|c|c|}
\hline 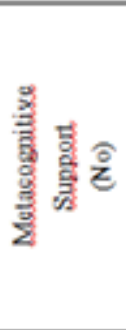 & $\begin{array}{l}\text { Second Problem } \\
\text { Third Problem } \\
\text { Equth Problem } \\
\text { Eifh Problem }\end{array}$ & $\begin{array}{l}1 \mathrm{~A} \rightarrow 1 \mathrm{~B} \rightarrow 1 \mathrm{D} \rightarrow 1 \mathrm{D} \rightarrow 1 \mathrm{~B} \rightarrow 1 \mathrm{~B} \rightarrow 1 \mathrm{D} \rightarrow 1 \mathrm{~B} \rightarrow 1 \mathrm{~A} \rightarrow 1 \mathrm{~B} \rightarrow 1 \mathrm{~A} \rightarrow 1 \mathrm{~B} \rightarrow 3 \mathrm{~A} \rightarrow 2 \mathrm{C} \rightarrow 3 \mathrm{~A} \rightarrow 2 \mathrm{~B} \rightarrow 1 \mathrm{~A} \rightarrow \\
2 \mathrm{C} \rightarrow 3 \mathrm{~A} \rightarrow 3 \mathrm{~A} \rightarrow 3 \mathrm{~A}-2 \mathrm{~B} \rightarrow 3 \mathrm{~A} \rightarrow 1 \mathrm{~B} \rightarrow 2 \mathrm{C} \rightarrow 3 \mathrm{~A} \rightarrow 4 \mathrm{~A} \rightarrow 3 \mathrm{~A} \rightarrow 3 \mathrm{~A}-2 \mathrm{C} \rightarrow 3 \mathrm{~A}-2 \mathrm{C} \rightarrow 3 \mathrm{~A} \rightarrow 3 \mathrm{C} \rightarrow 3 \mathrm{C} \rightarrow \\
3 \mathrm{C} \rightarrow 2 \mathrm{~B} \rightarrow 3 \mathrm{C} \rightarrow 4 \mathrm{~B} \rightarrow 1 \mathrm{D} \rightarrow 2 \mathrm{~B} \rightarrow 3 \mathrm{C} \rightarrow 3 \mathrm{~A} \rightarrow 2 \mathrm{C} \rightarrow 2 \mathrm{C} \rightarrow 2 \mathrm{C} \rightarrow 3 \mathrm{~A} \rightarrow 3 \mathrm{C} \rightarrow 3 \mathrm{C}-2 \mathrm{~B}-2 \mathrm{C} \rightarrow 3 \mathrm{~A} \rightarrow 4 \mathrm{~B} \rightarrow \\
4 \mathrm{~B} \rightarrow 3 \mathrm{C}-2 \mathrm{C} \rightarrow 3 \mathrm{~A} \rightarrow 2 \mathrm{C} \rightarrow 3 \mathrm{~A} \rightarrow 3 \mathrm{C} \rightarrow 4 \mathrm{~B} \rightarrow 2 \mathrm{~B} \rightarrow 2 \mathrm{~B} \rightarrow 4 \mathrm{~B} \rightarrow 2 \mathrm{~A} \rightarrow 2 \mathrm{C} \\
1 \mathrm{~A} \rightarrow 1 \mathrm{~B} \rightarrow 3 \mathrm{~B} \rightarrow 2 \mathrm{~B} \rightarrow 3 \mathrm{~A} \rightarrow 2 \mathrm{~B} \rightarrow 4 \mathrm{~B} \rightarrow 3 \mathrm{C} \rightarrow 2 \mathrm{~B} \rightarrow 3 \mathrm{~A} \rightarrow 3 \mathrm{~B}-2 \mathrm{~B} \rightarrow 3 \mathrm{~A} \rightarrow 4 \mathrm{~B} \rightarrow 2 \mathrm{~B} \rightarrow 3 \mathrm{C} \rightarrow 3 \mathrm{~A} \rightarrow 3 \mathrm{C} \rightarrow \\
4 \mathrm{~A} \rightarrow 2 \mathrm{C} \rightarrow 3 \mathrm{~A} \rightarrow 4 \mathrm{~A} \rightarrow 3 \mathrm{C} \\
1 \mathrm{~A} \rightarrow 1 \mathrm{~B} \rightarrow 2 \mathrm{~A} \rightarrow 3 \mathrm{~B} \rightarrow 3 \mathrm{~B} \rightarrow 3 \mathrm{~B} \rightarrow 3 \mathrm{~B} \rightarrow 3 \mathrm{~B} \rightarrow 3 \mathrm{~B} \rightarrow 3 \mathrm{C} \rightarrow 1 \mathrm{~A} \rightarrow 4 \mathrm{~A} \rightarrow 3 \mathrm{C} \rightarrow 3 \mathrm{C} \rightarrow 4 \mathrm{~A} \\
1 \mathrm{~A} \rightarrow 1 \mathrm{~B} \rightarrow 3 \mathrm{~B} \rightarrow 3 \mathrm{C} \rightarrow 4 \mathrm{~B} \rightarrow 3 \mathrm{~A} \rightarrow 2 \mathrm{~B} \rightarrow 3 \mathrm{C} \rightarrow 2 \mathrm{~B} \rightarrow 3 \mathrm{C}-2 \mathrm{~B} \rightarrow[\mathrm{C} \rightarrow 3 \mathrm{~A} \rightarrow 4 \mathrm{~A} \rightarrow 1 \mathrm{E} \rightarrow 1 \mathrm{E} \rightarrow 1 \mathrm{E} \rightarrow 1 \mathrm{E} \\
\text { Participant has to terminate the process }\end{array}$ \\
\hline 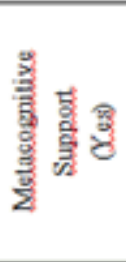 & $\begin{array}{l}\text { First Problem } \\
\text { Second Problem } \\
\text { Third Problem } \\
\text { Eourth Problem }\end{array}$ & $\begin{array}{l}1 \mathrm{~A} \rightarrow 1 \mathrm{~A} \rightarrow 1 \mathrm{~B} \rightarrow 1 \mathrm{D} \rightarrow 1 \mathrm{~B} \rightarrow 3 \mathrm{~A} \rightarrow 1 \mathrm{~B} \rightarrow 2 \mathrm{C} \rightarrow 2 \mathrm{C} \rightarrow 2 \mathrm{~B} \rightarrow 3 \mathrm{~A} \rightarrow 3 \mathrm{~A} \rightarrow 3 \mathrm{~A} \rightarrow 3 \mathrm{~A} \rightarrow 3 \mathrm{~A} \rightarrow 3 \mathrm{~A} \rightarrow 3 \mathrm{~A} \rightarrow 3 \mathrm{C} \rightarrow \\
1 \mathrm{~A} \rightarrow 1 \mathrm{~B} \rightarrow 4 \mathrm{~A} \rightarrow 4 \mathrm{~B} \\
1 \mathrm{~A} \rightarrow 1 \mathrm{D} \rightarrow 1 \mathrm{~B} \rightarrow 2 \mathrm{~A}-2 \mathrm{~B} \rightarrow 3 \mathrm{~A} \rightarrow 3 \mathrm{C} \rightarrow 2 \mathrm{~B} \rightarrow 3 \mathrm{~A} \rightarrow 3 \mathrm{C} \rightarrow 2 \mathrm{~B} \rightarrow 3 \mathrm{~A} \rightarrow 2 \mathrm{C} \rightarrow 2 \mathrm{~B} \rightarrow 2 \mathrm{C} \rightarrow 1 \mathrm{~B} \rightarrow 2 \mathrm{~B} \rightarrow 3 \mathrm{C} \rightarrow \\
4 \mathrm{~A} \rightarrow 4 \mathrm{~B} \rightarrow 3 \mathrm{C} \rightarrow 2 \mathrm{~B} \rightarrow 2 \mathrm{~B} \rightarrow 4 \mathrm{~A} \rightarrow 4 \mathrm{~A} \\
1 \mathrm{~A} \rightarrow 1 \mathrm{E} \rightarrow 1 \mathrm{~B} \rightarrow 1 \mathrm{D} \rightarrow 3 \mathrm{~B} \rightarrow 4 \mathrm{~A} \\
1 \mathrm{~A} \rightarrow 1 \mathrm{~B} \rightarrow 1 \mathrm{~B} \rightarrow 2 \mathrm{~B} \rightarrow 3 \mathrm{~A} \rightarrow 3 \mathrm{~A} \rightarrow 3 \mathrm{~A} \rightarrow 3 \mathrm{C} \rightarrow 4 \mathrm{~A} \rightarrow 4 \mathrm{~A} \\
1 \mathrm{~A} \rightarrow 1 \mathrm{C} \rightarrow 4 \mathrm{~B} \rightarrow 2 \mathrm{~B} \rightarrow 2 \mathrm{~A} \rightarrow 4 \mathrm{~A} \rightarrow 3 \mathrm{C}\end{array}$ \\
\hline
\end{tabular}

Table 12. Sequences of cognitive-metacognitive behaviours of $K 4.1$ coded participant

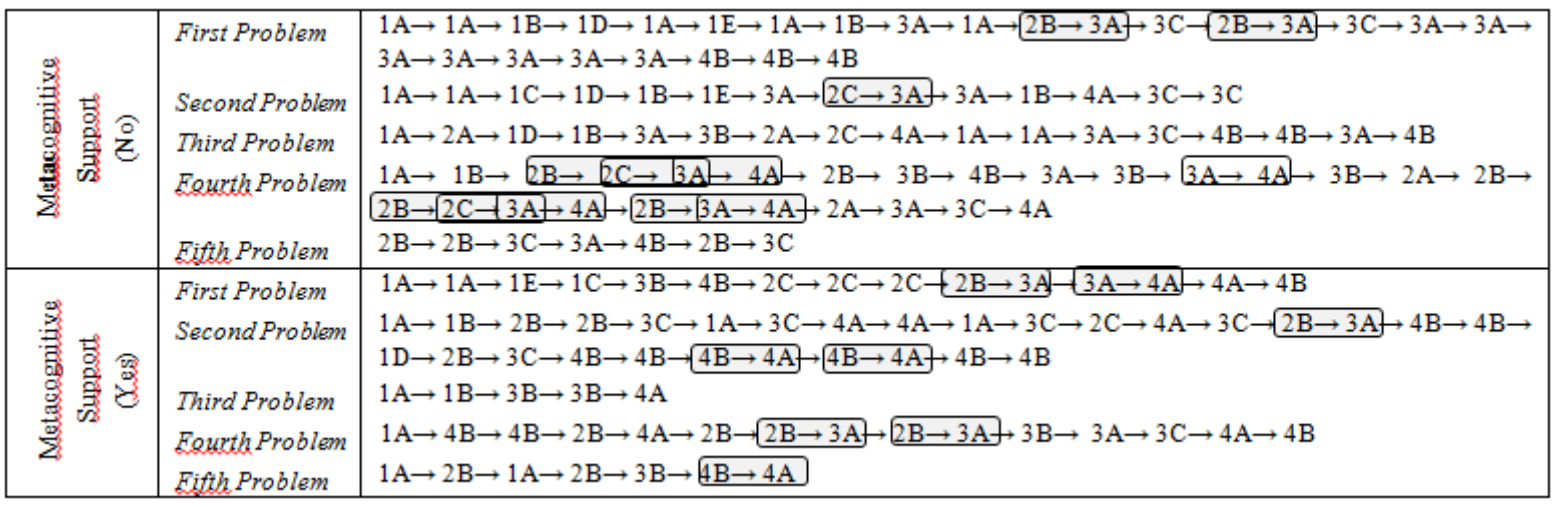

3.2.6. Sequences of Cognitive-Metacognitive Behaviours of K.3.2 Coded Participant

The findings related to the numbers of cognitive-metacognitive behaviours demonstrated by the K.3.2 coded participants within the scope of baseboard problem during the stages with and without metacognitive support are indicated in Table 11.

According to the data in Table 11, the participant in each situation started solving all of the problems with $1 \mathrm{~A}$. During the protocols without metacognitive support, $1 \mathrm{~A}$ behaviour was demonstrated 4 times after the cognitive-metacognitive behaviours and during the protocols with metacognitive support twice.

During the protocols without metacognitive support of the participant, 3A behaviour followed 2C 11 times, but during the protocols with metacognitive support, such a sequence was not encountered. Especially, during the protocols without metacognitive support, $3 \mathrm{~A}$ behaviour followed $2 \mathrm{~B}$ behaviour. While 3B behaviour was demonstrated after 3B during the protocols without metacognitive support, it was demonstrated only once during the protocols with metacognitive support. During the protocols without metacognitive support, 3C behaviour generally demonstrated after 3C, but during the protocols with metacognitive support, such a generalization was not encountered. The behaviour sequence as $2 \mathrm{~B} \rightarrow 2 \mathrm{C} \rightarrow 3 \mathrm{~A}$ was demonstrated once in 1st and 4th questions only during the protocols without metacognitive support.

Moreover, during the protocols without metacognitive support of the participant, $3 \mathrm{~A}$ followed $2 \mathrm{~B}$ four times, and 5 times during the protocols with metacognitive support. The participant, during the protocols without metacognitive support of the participant, finished the problem solving process with $2 \mathrm{C}, 3 \mathrm{C}, 4 \mathrm{~A}$ and $1 \mathrm{E}$ in order, but during the protocols with metacognitive support, finished the process with $4 \mathrm{~A}$ three times, $4 \mathrm{~B}$ once and $3 \mathrm{C}$ once. During the protocols without metacognitive support, $4 \mathrm{~A}$ behaviour was demonstrated after $3 \mathrm{~A}$ most (3 times), during the protocols with metacognitive support it was demonstrated after $3 \mathrm{C}$ and $4 \mathrm{~A}$ most (twice).

\subsubsection{Sequences of Cognitive-Metacognitive Behaviours of} K.4.1 Coded Participants

The findings related to the numbers of cognitive-metacognitive behaviours demonstrated by the K.4.1 coded participants within the scope of baseboard problem during the stages with and without metacognitive support are indicated in Table 12. 
According to the data in Table 12, K.4.1 coded participant in each situation started solving all of the problems with $1 \mathrm{~A}$. During the protocols without metacognitive support, $1 \mathrm{~A}$ was demonstrated 6 times after cognitive-metacognitive behaviour, during the protocols with metacognitive support 4 times. During the protocols without metacognitive support, while $1 \mathrm{~B}$ behaviour generally was demonstrated after $1 \mathrm{~A}$ and $1 \mathrm{D}$, it was demonstrated after $1 \mathrm{~A}$ during the protocols with metacognitive support.

During the protocols without metacognitive support of the participant $3 \mathrm{~A}$ behaviour followed $2 \mathrm{C} 3$ times, but during the protocols with metacognitive support, such a sequence was not demonstrated. While $3 \mathrm{C}$ behaviour was generally demonstrated after $3 \mathrm{~A}$ during the protocols with metacognitive support, such situation was not demonstrated during the protocols with metacognitive support. The behaviour sequence as $2 \mathrm{~B} \rightarrow 2 \mathrm{C} \rightarrow 3 \mathrm{~A}$ was only demonstrated in the 4 th question during the protocols with metacognitive support.

Moreover, during the protocols without metacognitive support of the participant, $3 \mathrm{~A}$ behaviour followed 2B 3 times, but during the protocols with metacognitive support 4 times. During the protocols without metacognitive support, while the participant finished the problem solving process twice with $3 \mathrm{C}$, twice with $4 \mathrm{~B}$, and once with $4 \mathrm{~A}$, but during the protocols with metacognitive support three times with $4 \mathrm{~B}$ and twice with 4A. During the protocols without metacognitive support, $4 \mathrm{~A}$ behaviour was demonstrated after $3 \mathrm{~A}$ most (4 times), during the protocols with metacognitive support after 4B most (4 times).

3.2.8. Sequences of Cognitive-Metacognitive Behaviours of K.4.2 Coded Participant
The findings related to the numbers of cognitive-metacognitive behaviours demonstrated by the K.4.2 coded participants within the scope of baseboard problem during the stages with and without metacognitive support are indicated in Table 13.

According to the data given in Table 13, the participant in each situation, started solving all of the problems with $1 \mathrm{~A}$. During the protocols without metacognitive support, 1A behaviour was demonstrated after cognitive-metacognitive behaviour 10 times, during the protocols with metacognitive support, it was demonstrated once after cognitive-metacognitive behaviour.

During the protocols without metacognitive support of the participant $3 \mathrm{~A}$ behaviour followed $2 \mathrm{C} 4$ times, during the protocols with metacognitive support 4 times. During the protocols without metacognitive support, $3 \mathrm{C}$ behaviour was generally demonstrated after $3 \mathrm{C}$ during the protocols with metacognitive support, it was demonstrated generally after 4B. The behaviour sequence as $2 \mathrm{~B} \rightarrow 2 \mathrm{C} \rightarrow 3 \mathrm{~A}$ was demonstrate only in the 2 nd question during the protocols with metacognitive support.

Moreover, during the protocols with metacognitive support 3A followed 2B 3 times. During the protocols without metacognitive support, while participant finished the problem solving process with $3 \mathrm{C}$ four times and $4 \mathrm{~A}$ once, during the protocols with metacognitive support, he finished the process 3 times with $4 \mathrm{~B}$ and twice with $4 \mathrm{~A}$. During the protocols without metacognitive support, $4 \mathrm{~A}$ behaviour was demonstrated most (twice) after $3 \mathrm{C}$ behaviour, during the protocols with metacognitive support after $4 \mathrm{~B}$ most $(7$ times).

Table 13. Sequences of cognitive-metacognitive behaviours of K 4.2 coded participant

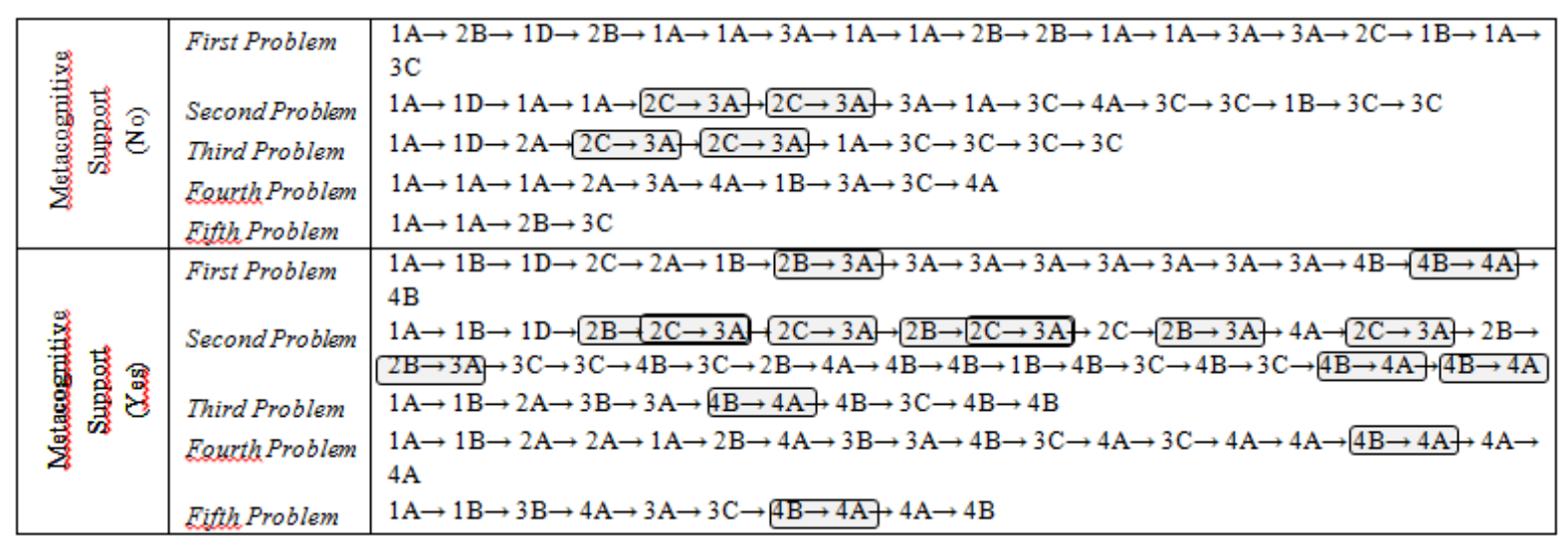




\subsection{Findings Related to the Research Question 'Does the sequence of demonstrated cognitive-metacognitive behaviours by pre-service teachers in mathematical modelling processes vary according to the occasions with and without metacognitive support in terms of the class variable?'}

In order to give answer to this sub-problem, the answers to the question 'If you want to compare the 1st stage in which the metacognitive support is given with the second stage in which metacognitive support is not given, how do you evaluate' by the participants were presented in order considering the class level.

K.1.1 coded participant expressed his thoughts, as 'I don't think that the problem is too difficult but it required attention, and I always have lack of attention. At first stage, as I did not think of the other side of the room, all of the procedure was incorrect. At the second stage, as I was enabled to see here, thus, the rest of the problem became correct easily. Generally, as a student, we quit directly after reaching the first solution, it is the same as in exams and as usual, there is no examine.' The participant, in the expressions, pointed out the attention that the second stage enabled him. The participant, immediately after reading and trying to understand the question at first stage, set the mathematical model. Calculating the perimeter of the room as $21+28=49 \mathrm{~m}$, did not realise that he calculated it incorrectly, as he set his model as $10 x+16 y=49$, he conducted all of the processes related to the problem according to this. The participant, at the second stage, noticed that he had made a mistake and stated that all the results should be doubled indeed. Yet, the participant did not use the mathematical model, which he settled both in the first and second stage during the solving process. Although he reached the correct solution in 3rd and 5 th problems at the second stage, he reached the incomplete solution in the first and second problem and he finished the process with an incorrect solution in the fourth question. Therefore, the expressions of K.1.1 coded participant confirm the behaviours within the process of mathematical modelling in both of the stages.

K.1.2 coded participant expressed his thoughts as 'Firstly, at the second stage, my ways of solution almost completely changed or alternative solutions came out. I do not think I completely understood the question at first stage. Yet, your interventions at the second stage, made me think more and I got better results.' The participant, in the expressions, pointed out that he could think more on the questions thanks to the second stage and as a result, changed the ways, found alternative ways of solution and reached better results. The participant, at first stage read the first problem during the solving process, drew a shape, made plans, calculated his plans and claimed the result of the problem as 10 of $10 \mathrm{~m}$ and 2 of $16 \mathrm{~m}$ boards should be used. The participant was not aware that the room's diameter is more than his use of such amount of baseboards. The participant did not develop any mathematical model in the second stage during the problem solving and used the expression, as 'There are many ways to solve this problem, because there is no restriction' several times. The participant tried to develop alternative ways for the solution of the problem but gave results, which exceeded the length of the room again. (For instance; 8 of $10 \mathrm{~m}$ and 4 of 16). During the protocol without metacognitive support, the participant reached a correct solution for the second question but he could not reach a solution because of the incorrect calculations. Yet, the participant, in the second occasion, noticed the incorrect operations and recommended a different way of solution. In the third problem, while the participant found a result in which he increased $2 \mathrm{~m}$ at first stage, he was able to solve the problem without increasing. This participant found a solution (10 of $16 \mathrm{~m})$ even in the 5 th question in which exceeded the length of the room fairly. The participant was not able to understand the problem much indeed. Therefore, the expressions of K.1.2 coded participant confirm the behaviours within the process of mathematical modelling in both of the stages.

K.2.1 coded participant expressed his thoughts, as 'At first, I could not solve the problem. Then you did not give any information indeed but I could solve it then. Thanks to that you get us think about the questions continually, I started to solve the problem.' The participant expressed that he could think more on the questions thanks to the second stage. K.2.1 coded participant claiming that he found the questions enclosed at first stage he finished the problem solving process. At the second stage, the participant did not develop mathematical model in the first question. The participant gave some expressions, as 'As the baseboards are 10 and 16 $\mathrm{m}$, taking their exact multiples I will calculate through trial and error'. After this process of trial and error, the participant expressed the only solutions reaching 98 exactly ( 3 of $16 \mathrm{~m}$ and 5 of $10 \mathrm{~m}$ ) and he increased at least 2 meters ( 5 of $16 \mathrm{~m}$ and 2 of $10 \mathrm{~m}$ ). Therefore, the expressions of K.2.1 coded participant confirm the behaviours within the process of mathematical modelling in both of the stages.

K.2.2 coded participant expressed his thoughts as 'I read the problem at first but I did not understand what it means. As you asked me question, I started to understand it and my procedure and solution changed automatically.' The participant pointed out that the second stage gave him the possibility to understand the problem. K.2.2 coded participant, at first stage, especially in the first problem, read it several times and tried to make it meaningful. As it is understood from the expressions of the participant: 'As it does not refer the least or most, I divide all of them with 1 and take the rest of them. Thus, I use 28 of them for the length and 21 for the width. That means I use 98' he really had difficulty in understanding the first question. At the second stage, the participant developed a mathematical modelling during the solving process of the first problem and reached the solution thanks to this model. Therefore, the expressions of K.2.2 coded participant confirm the behaviours within the process of mathematical modelling in both of the stages.

K.3.1 coded participant expressed his thoughts as 'Turning the questions again and again I checked the results, 
I was sure about some of them but this created a negative result for the second question in the problem. The first that I thought was more correct.' The participant pointed out that the second stage gave him the possibility to check the results but this became a negative way for a question for him. As K.3.1 coded participant, at the second stage, noticing the mistakes that he made at the first stage used some sentences as 'I have misunderstood here, I solved this incorrectly, and I check if this is correct or not, I think it is correct'. Therefore, the expressions of K.3.1 coded participant confirm the behaviours within the process of mathematical modelling in both of the stages.

K.3.2 coded participant expressed his thoughts, as 'Of course there were differences between the first stage and the second stage. There were several occasions in which I said 'oh, I may make this here' and I did several things.' The participant pointed out that the second stage gave him the possibility to understand the problem. K.3.2 coded participant made a significant effort in order to solve the problems at first stage, claimed that there may be different ways of solving it during the process but could not limit the possibilities. During the second stage, the participant developed the mathematical model and thus made much faster correct solutions. When the participant developed the mathematical model at first stage, he wrote $10 n+16 m=98$ and he used an expression with smiling as 'that is to say, it depends on our point of view to the problem'. The participant, again at the first stage, claimed to use 9 of $10 \mathrm{~m}$ as an answer for the third problem but he did not notice that $90 \mathrm{~m}$ would not cover the room entirely. The participant, during the second stage, expressed that the model he developed for the problem as $n=5$ and $m=3$ that checked the model, that there is no waste and this procedure quite persuade him. The participant, during the first stage, after a few numbers of calculating the alternatives enabling the lowest cost for the fourth question, he expressed his thoughts as 'I, presumably, will continue with this problem till the morning, is this problem very difficult or I cannot solve it, I will solve through this way, but there are several ways, I take it there, I take this here.' Yet, at the second stage, this participant, calculating the costs of all the possibilities in his mathematical model, expressed the correct result with the lowest cost. Therefore, the expressions of K.3.2 coded participant confirm the behaviours within the process of mathematical modelling in both of the stages.

K.4.1 coded participant expressed his thoughts as 'Question marks appeared in my mind. As we are usually in race with time, we cannot regard several things during the exams. Actually, at first stage, I knew that there were several ways of reaching the result but I thought that there was no need to try. I think that the second stage is useful that I could criticize myself.' In his expressions, the participant expressed that the second stage gave him opportunity for developing new solutions for the problems. K.4.1.coded participant, at first stage, during the solving process of the first problem, thinking that they can use both $10 \mathrm{~m}$ and $16 \mathrm{~m}$ baseboards, decided that they can cover the entire room with
10 of $10 \mathrm{~m}$, or 7 of $16 \mathrm{~m}$ baseboards. Then, he finished the solving process of the first problem thinking of 'I might reach this result using two different kinds of baseboards, too but as the way I will have to follow completely depends on me, I may reach totally different results, I don't want to do this.' That is the K.4.1coded participant, actually, is aware that there are different ways to solve the first problem at first stage too, but he did not want to do these operations. Yet, as the participant, at the second stage, answered the question 'Are those the sole solutions?' with no, tried to solve the problem again, developed his mathematical model and then found out all the possible solutions of the problem. The participant, even in the second problem reached a solution with 8 joints most, developed different ways of solution in the second stage. The participant, during the first stage, claimed the results of the third problem without using mathematical model as using 5 of $10 \mathrm{~m}$ or 3 of $16 \mathrm{~m}$ and then checked it as he stated in his expression 'The multiplication of those will give the diameter of the room and thus, we provide a crosscheck.' At the second stage, he answered the question 'what does this question mean' directed to him as 'the less boards waste, the better it is. In order to find it as little as possible, I found a solution giving no waste and I checked it.' Then the participant looking for the equations of his model developed in the first problem, he finished the process saying 'We have only once reached to 98 . So, that is the correct solution, there is no more solution.' Therefore, the expressions of K.4.1 coded participant confirm the behaviours within the process of mathematical modelling in both of the stages.

K.4.2 coded participant expressed his thoughts as 'In terms of the practicability, at the second stage, I noticed to think of different possibilities and different choices.' The participant pointed out that the second stage gave him the opportunity to develop new solutions for the problems. At first stage, K.4.2 coded participant, during the solving process of the first problem, after demonstrating $1 \mathrm{~A}$ and $2 \mathrm{~B}$ codes, developed his mathematical model as $10 x+16 y=98$ and at first, thought about the equation giving it some values. Then, the participant following the operations of $98: 16=6$ and $98: 10=9$, finished the process claiming that he can cover the room using 7 of $16 \mathrm{~m}$ or 10 of $10 \mathrm{~m}$ boards. In this stage, although the participant developed a mathematical model, he gave up calculating the numbers of $10 \mathrm{~m}$ and $16 \mathrm{~m}$ boards, which provide his model immediately, tried a different way of solution. Although this way and solution of the participant was correct, it was deficient as it was two ways of solution only. In the second stage, the participant found all the ways of solution, which provide his mathematical model. Moreover, he finished the solving process claiming 'Different ways may exist, this solution persuaded me.' The participant stated that he could solve the problem with 8 joints at first stage and provide this solution using 6 of $16 \mathrm{~m}$ boards and 1 of $10 \mathrm{~m}$ board. At the second stage, the participant providing to protect the number of the joints as 8 , developed two more ways of solution. The participant at first stage using 6 of $16 \mathrm{~m}$ and 2 of $10 \mathrm{~m}$ boards, he wasted $18 \mathrm{~m}$, 
at the second stage, finding the solution as $98 \mathrm{~m}$ through his mathematical model, stated that the room can be covered without any waste of boards. Therefore, the expressions of K.4.2 coded participant confirm the behaviours within the process of mathematical modelling in both of the stages.

\section{Conclusion and Discussion}

The carried study aims to investigate pre-service teachers' cognitive-metacognitive behaviours in the mathematical modelling problem-solving process with and without metacognitive support considering the class level. In this section, the results are going to be presented depending on the sub-problems.

The results within the scope of the first sub-problem of the research as 'Do the numbers of cognitive - metacognitive behaviours demonstrated by the pre-service teachers during the stages of mathematical modelling vary in terms of the class variable in a case with and without metacognitive support? 'can be described as follows;

With a general view, the demonstration sequence of the numbers of cognitive- metacognitive behaviours demonstrated during the mathematical modelling process from the most to the least within the scope of grades, during the protocols without metacognitive support is as 3-4-1-2 and during the protocols with metacognitive support as 1-2-3-4. Totally the behaviours were demonstrated by the participants among 3rd graders most and 4th graders least. Though the first and second classes demonstrated the most cognitive-metacognitive behaviours, there are also cases in which they were not able to be successful. This result is in parallel with the situation that shows the increase in the demonstration of metacognitive behaviours does not ensure the success [43].

The participants, during the grasp stage of the mathematical modelling process, in which it is tried to understand the requirements and being aware of and expressing limitations of the real system, they demonstrated mostly the behaviours of reading the problem and trying to understand the problem. During the stage of resembling to mathematics of mathematical modelling process in which the real situation is prepared for the mathematical operations and, in a way, constructing the model and formulizing the real situation they developed mathematical models mostly by making general and special plans. During the stage of solving the model, in which the mathematical model reach the result by appropriate mathematical operations and solve our problem, the applications of the model and the last mathematical results are interpreted to real situation of mathematical modelling process, the participants mostly made mathematical operations and demonstrated the result behaviours related to these operations. During the stage, in which the model is checked and interpreted mathematical modelling process before solving the model, under the present condition, the behaviour of the real system redeveloped thanks to the model and achieved, the participants demonstrated mostly the behaviours of checking the results, making crosscheck and developing alternative solutions.

During the mathematical modelling process with and without metacognitive support, first graders mostly demonstrated the behaviours in order as making mathematical operations and making special plans for the solution of the problem. Related to this, it is possible to express that it is an indicator of providing metacognitive support does not change the behaviours, which the individuals prefer in mathematical modelling process much. Yet, providing metacognitive support contributed to the occurrence some cognitive-metacognitive behaviours and the frequency of some behaviour. For instance, while the behaviours of checking the procedure, crosschecking, developing alternative ways of solution was almost never demonstrated by several participants during the process with metacognitive support, during the protocols with metacognitive support was the most demonstrated behaviour. After the metacognitive support, the behaviour of checking the consistencies of the reached results with the data in the problems was the behaviour, which is the most frequent in every grade. Even in the study by Ellerton [60] during their problem solving experiences, it was proved that the students demonstrate higher metacognitive behaviours as they started to understand the role of reflection. Aydemir and Kubanç [30], pointed out that the students, who can use metacognitive skills, can develop alternative ways and reach the correct solution; on the other hand ones, who cannot use the metacognition skills reach the solution with ordinary methods.

The results within the scope of the second sub-problem of the research as 'Do the sequence of demonstrated cognitive-metacognitive behaviours by pre-service teachers in mathematical modelling processes vary according to an occasion with and without metacognitive support in terms of the class variable?' is described as follows.

All the participants placed in the study group, (except from one question of K.3.1 coded participant) started all of the mathematical modelling processes with reading the problem but they read the problem during the process from time to time, repeatedly. The behaviour of reading question was demonstrated after cognitive-metacognitive behaviour 38 times during the stage without metacognitive support and 27 times with metacognitive support. During the stage without metacognitive support, the numbers of re-reading metacognitive behaviours reduced. The behaviour of reading the question, which was demonstrated by the participants during the stage without metacognitive support, were observed mostly after the behaviour of reading the problem (18 times), trying to understand the problem (6 times) and making calculations (5 times), during the stage with metacognitive support were mostly after reading the problem (9 times), trying to understand the problem (4 times) and writing the result ( 3 times). That is, the participants re-read the problem, after reading the problem, after trying to understand the problem, after making the operations related 
to the problem and after reaching the solution of the problem. Although the behaviour of re-reading the problem has the least frequency, it was demonstrated after drawing a figure related to the problem, after thinking of its difficulty, after making a plan related to the solution of the problem, and after checking the consistency of the gathered results with the problem. Yimer and Ellerton[16], also, stated that pre-service teachers might read the problem repeatedly for different purposes.

One of the patterns of the participants during the process of mathematical modelling process is demonstrating the behaviour of; making mathematical operations after making special plans for the solution of the problem. That is, the participants, after specialized with shortening their plans related to the solution of the problem, did the evaluations of these plans. While the sequence of these behaviours by K.1.1, K.1.2, K.2.1, K.2.2, K.3.1, K.3.2, K.4.1 and K.4.2 coded participants during the protocols without metacognitive support come out entirely, in order with the frequency of; 5 , $12,0,3,12,11,3,4$, during the protocols with metacognitive support orderly as the frequency of $21,12,22$, $12,6,0,0,4$. While the use of these behaviours shows increase or equality from without metacognitive support to with metacognitive supporting 1 st and 2 nd grades, it came out as reduce or equality in the 3 rd and 4 th grades.

One of the patterns encountered during the study was making mathematical operations after the behaviour of making general plans about the solution of the problem. That is the participants making some restrictions in their general plans related to the solution of the problem then made the calculations within the scope of these plans. While the sequence of the K.1.1, K.1.2, K.2.1, K.2.2, K.3.1, K.3.2, K.4.1 and K.4.2 coded participants' behaviours come out orderly, in the protocols without metacognitive support is totally with the frequencies as $0,1,0,2,1,4,3,0$, it occurred in the protocols with metacognitive support in order as $0,2,0$, $3,8,5,4,3$ frequencies. Demonstrating these behaviours one after another increases in all the classes from those without metacognitive support to those with metacognitive support, moreover, the highness in the frequencies in 3rd and 4th grades compared to 1 st and 2 nd grades is remarkable. Considering the reduce of the participants' demonstrating the behaviours making mathematical operations after the behaviour of making special plans for the solution of the problem, specifically in 3rd and 4th grades, the result mentioned about becomes considerable. Shortly, it can be expressed that the students in $3 \mathrm{rd}$ and 4 th grades continued with calculations without specializing their plans related to the solution of the problem much.

Another point that is remarkable among the participants in the process of mathematical modelling is that the behaviour of confirming the solutions with the data in the problem, during the protocols without metacognitive support, coming after making calculations most (19 times),then, after making special plans related to the solution of the problem (5 times). The demonstration of this behaviour came after the behaviour of making calculations most (22 times) during the protocols with metacognitive support, after the behaviour of confirming the reached results with the data in the problem most (21 times), and after result check, crosscheck, developing alternative solutions (17 times). That is, the participants, after making operations during the protocols without metacognitive support and making specialized plans related to the solution of the problem, confirmed those results with the data in the problem. During the protocols with metacognitive support, the participants again, after making operations and developing alternative solutions to the problem or after checking the results of the problem, confirmed those results with the data in the problem.

The remarkable point related to the demonstration of the behaviours result check, crosscheck, developing alternative solutions by the participants during the process of mathematical modelling is the demonstration of this behaviour mostly after itself. That is, the participants demonstrated the behaviours repeatedly after the behaviours of developing alternative solutions to the problem or checking the results, making crosscheck.

During the mathematical modelling process of the participants, apart from the binary patterns, a triple pattern was also encountered. The behaviour pattern as making a general plan related to the solution of the problem, specializing the plans and making calculations in every grades, was used 3 times, in average, sometimes without metacognitive support, sometimes with metacognitive support and sometimes in both of the two stages. In the occurrence of this behaviour pattern, any difference was not encountered according to the class level and metacognitive support.

Even in the study by Yimer and Ellerton[16], any general pattern was not encountered in the problem solving process of pre-service teachers demonstrating metacognitive behaviours, also it was noticed that the solving process of the same students in different problems were also different. Demircioğlu, Argün and Bulut [32] emphasized the same result. The researchers were not encountered with any pattern demonstrated by the pre-service teachers in terms of metacognitive in their academic success, but reached the result that different types of the problems affect the number of metacognitive behaviours.

The results within the scope of the third sub-problem of the research as 'How do the pre-service teachers evaluate the mathematical modelling processes in terms of with and without metacognitive support?' can be described as follows. Artzt, \& Armour-Thomas[4], in their studies, claimed that the pre-service teachers returned to the steps reading the problem, analysing, discovering etc. again and again in the process of problem solving. Aydemir and Kubanç [30] pointed out that the students, who can use their cognitive skills, do not fulfill the stages of metacognition in order and they skip some steps during the problem solving process.

The participants expressed that the second stage enabled them the attention, thinking about the questions, checking and thinking of different ways of solutions. The expressions of the participants from the 1st and 2 nd grades were mainly 
on reading and understanding the problem but the participants from 3rd and 4th grades answers were mainly on following the operations, checking and confirming the results and developing different ways of solutions for the problems. Giving metacognitive support directed the participants to the behaviours as thinking on the problems more, understanding the problems, turning back to the questions again. Thus, it can be expressed that metacognitive support, enabling the participants to follow-check and find new ways of solutions, affected the mathematical modelling process positively. To sum up, considering the fact that participants are more successful in the process of mathematical modelling during the protocols with metacognitive support, it can be expressed that all of the cognitive-metacognitive behaviours as confirming the results with the data in the problem, developing alternative ways of solutions have significant role for the success in the process of mathematical modelling. This result is in parallel with most of the participants' claims that the metacognitive knowledge in modelling process contributed much to them in the study by Maab[44]. Similarly, it coincides with the expressions of most of the pre-service teachers as; 'By use of my metacognition, I remind myself to keep checking my solution with the problem to make sure I solve it correctly' in the study by Yimer and Ellerton[16]. Consequently, it can be claimed that the participants are much more successful in the process of mathematical modelling during the stage in which metacognitive support was given to the participants. These results are in paralel with the results of the studies $[4,19,20,29,30,40,48,66]$ which show that the problem solving success increased with metacognitive support and teaching strategy. Takahashi \& Murata[81] also reached the result showing the teaching of metacognition has a form, which activates metacognition for understanding and directing the problem solving process.

In general, it was noticed that giving metacognitive support during the process of mathematical modelling increased the numbers of cognitive-metacognitive behaviours. Within the scope of the study, it was recognised that the participants did not have a fixed template in the process of mathematical modelling both with and without metacognitive support. It was noticed that, in both stage, the participants demonstrated some cognitive-metacognitive behaviours one after another. It can be expressed that the metacognitive support contributed much advantages within the participants' point of view.

As the results were analysed within the perspective of mathematical model and modelling, it can be claimed that the metacognitive support helped the participants in developing mathematical model and thus, they were able to reach the correct and alternative solutions. Therefore, the participant could develop different ways of solutions thanks to their models or easily expressed that they were sure about the results. For instance, in the 3rd question, the participants could claim that is the result, the only result considering their model, because, only this solutions gives the zero. When the metacognitive support was not given, developing the mathematical model was only developed by K.1.1 and K.4.2 coded participants but the participants did not apply the model as a tool in reaching the result. In the protocols with metacognitive support, five participants (K.1.1, K.2.2, K.3.2, K.4.1, and K.4.2) developed the mathematical model and the participants were able to use this model through their goals. When the mathematical modelling processes of the participant are investigated, the behaviours of developing mathematical modelling and reaching the results with the help of this model, it is noticed that these behaviours are achieved well in the grades of 3rd and 4th. Therefore, we can express that giving the metacognitive support in the process of mathematical modelling influenced the participants' developing mathematical model, and applying the model for their purposes positively, and this effect was higher in 3rd and 4th grades.

Another result which was reached in terms of mathematical model and modelling is that the participants always developed their mathematical models directly. These participants decided to develop a mathematical model because of the insolubility, the useless of the plans, disability to limit the possibilities, reached decisions as a result of the calculations which they encountered during the process. The behaviours of making mathematical operations on the model and reaching the result are the most encountered behaviours, which the participants demonstrated during the process with metacognitive support. The behaviours as testing the model, interpreting and evaluating are the behaviours, which are mostly demonstrated by the upper graders.

The study is limited with only one metacognitive support to the pre-service teachers in the process of mathematical modelling and so, it is not among the prior goals that the pre-service teachers to internalize these behaviours totally after the first metacognitive support. In following studies, it is thought that it will contribute to the literature much to investigate the effects of this situation on the mathematical modelling processes and the permanents of these effects with handling more detailed and systematically.

\section{REFERENCES}

[1] A. Desoete, M. V. J. Veenman. Metacognition in mathematics: Critical issues on nature, theory, assessment and treatment. In A. Desoete \& M. V. J. Veenman (Eds.), Metacognition in mathematics education (pp. 1-10). Nova Science Publishers, New York, 2006.

[2] A. Desoete. Metacognitive prediction and evaluation skills and mathematical learning in third-grade students, Educational Research and Evaluation, No.15, 435-446. 2009.

[3] A. E. Jacobse, E. G. Harskamp. Towards efficient measurement of metacognition in mathematical problem solving, Metacognition Learning, Vol.7, No.2. 133-149. 2012.

[4] A. F. Artzt, E. Armour-Thomas. Development of a cognitivemetacognitive framework for protocol analysis of 
mathematical problem solving in small groups. Cognition and Instruction, No. 9, 137-175.1992

[5] A. F. Artzt, E. Armour-Thomas. Mathematical problemsolving in small groups: Exploring the interplay of students' metacognitive behaviours, perceptions, and ability levels, Journal of Mathematical Behavior, No.16, 63-74. 1997.

[6] A. F. Artzt, E. Armour-Thomas. Mathematics teaching as problem solving: A framework for studying teacher metacognition underlying instructional practice in mathematics. Instructional Science, No. 26, 5-25. 1998

[7] A. H. Schoenfeld. Expert and novice mathematical problem solving, Final Project Report and Appendices BH, 1982.

[8] A. H. Schoenfeld. Learning to think mathematically: Problem solving, metacognition, and sense making in mathematics. In D. A. Grows (Ed.), Handbook of research on mathematics teaching and learning (pp. 334-370). Macmillan, New York, 1992.

[9] A. H. Schoenfeld. Making sense of "out loud" problem solving protocols, The Journal of Mathematical Behavior, No.4, 171-191. 1985.

[10] A. H. Schoenfeld. Problem solving from cradle to grave, Annales de Didactique et de Sciences Cognitives, No.11, 4173. 2006.

[11] A. H. Schoenfeld. What's all the fuss about metacognition? In A. H. Schoenfeld (Ed.), Cognitive science and mathematics education (pp. 189 - 215). NJ: Lawrence Erlbaum Associates, Hillsdale, 1987.

[12] A. K. Ellis, J. B. Bond, D. W. Denton. An analysis of research on metacognitive teaching strategies, Procedia - Social and Behavioral Sciences, No.116, 4015 - 4024. 2013

[13] A. K. Ellis, J. B. Bond, D. W. Denton. An analytical literature review of the effects of metacognitive teaching strategies in primary and secondary student populations, Asia Pacific Journal of Educational Development, Vol.1, No.1, 9-23. 2012.

[14] A. Yıldırım, H. Şimşek. Sosyal bilimlerde nitel araştırma yöntemleri (5. Baskı). Seçkin Yayıncılık, Ankara, 2006.

[15] A. Yimer. Metacognitive and cognitive functioning of college students during mathematical problem solving. Unpublished doctoral dissertation, Illinois State University, IL. 2004

[16] A. Yimer, N. F. Ellerton. A five-phase model for mathematical problem solving: Identifying synergies in pre-service-teachers' metacognitive and cognitive actions, ZDM Mathematics Education, No.42, 245-261. 2010.

[17] A. Zohar, Teachers_ metacognitive knowledge and the instruction of higher order thinking, Teaching and Teacher Education, No.15, 413-429. 1999.

[18] B. Çetin. An investigation of teacher candidates' metacognitive skills according to their year of study at Çanakkale, Educational Research and Review, Vol.10, No.1, 10-16. 2015.

[19] B. Kramarski, Z.R. Mevarech, A. Liberman. The effects of multilevel- versus unilevel metacognitive training on mathematical reasoning. Journal for Educational Research, Vol. 94, No.5, 292-300. 2001.
[20] B. Kramarski, Z.R. Mevarech, M. Arami, The effects of metacognitive instruction on solving mathematical authentic tasks. Educational studies in mathematics, Vol.49, No.2, 225-250. 2002.

[21] C. T. Yang, S. Y. Lee. The effect of instruction in cognitive and metacognitive strategies on ninth-grade students' metacognitive abilities, New Waves-Educational Research \& Development,Vol.16, No.1, 46-55. 2013.

[22] C. Quintana, M. Zhang, J. Krajcik. A framework for supporting metacognitive aspects of online inquiry through software-based scaffolding. Educational Psychologist, Vol.40, No.4, 235-244. 2005.

[23] D. H. Jonassen. Instructional design models for well-structured and Ill-structured problem solving learning outcomes, Educational Technology Research and Development, Vol.45, No.1, 65-94. 1997.

[24] D. L. Kroll, T. Miller. Insights from research on mathematical problem solving in the middle grade. In D. Owens (Ed.) Research ideas for the classroom: Middle grade mathematics (pp. 8-27). VA: NCTM, Reston, 1993.

[25] F. Depaepe, E. D. Corte, L. Verschaffel. Teachers' metacognitive and heuristic approaches to word problem solving: analysis and impact on students' beliefs and performance, ZDM Mathematics Education, No.42, 205-218. 2010 .

[26] F. K. J. Lester, J. Garofalo, D. L. Kroll. The role of metacognition in mathematical problem solving: a study of two grade seven classes, Final Report, 1989.

[27] F. K. J. Lester. Musings about mathematical problem-solving research: 1970-1994. Journal for Research in Mathematics Education, Vol.25, No.6, 660-675. 1994.

[28] G. Kaiser, B. Schwarz. Mathematical modelling as bridge between school and university, Zentralblatt Für Didactik Der Mathematic, Vol.38, No.2, 196 - 208. 2006.

[29] G. Özsoy, A. Ataman. The effect of metacognitive strategy training on mathematical problem solving achievement. Online Submission, Vol.1, No.2, 68-83. 2009.

[30] H. Aydemir, Y. Kubanç. Problem çözme sürecinde üstbilişsel davranışların incelenmesi. Electronic Turkish Studies, Vol.9, No.2, 39-58. 2014.

[31] H. A. Simon. The structure of ill-structured problems, Artificial Intelligence, No.4, 181-202. 1973.

[32] H. Demircioğlu, Z. Argün, S. Bulut. A case study: assessment of preservice secondary mathematics teachers' metacognitive behaviour in the problem-solving process, ZDM Mathematics Education, No.42, 493-502. 2010.

[33] H. M. Doerr, L. D. English. Middle grade teachers' learning through students' engagement with modeling tasks, Journal of Mathematics Teacher Education, No.9, 5-32. 2006.

[34] J. Berry, K. Houston. Mathematical modeling. Edward Arnold, London, 1995.

[35] J. Dunlosky, J. Metcalfe. Metacognition. A Textbook for cognitive, educational, life span \& applied psychology, CA: Sage Publications, Thousand Oaks 2008.

[36] J. Garofalo, F. K. Lester. Metacognition, cognitive monitoring and mathematical performance, Journal for 
Research in Mathematics Education, Vol.16, No.3, 163-176. 1985.

[37] J. H. Flavell. Metacognitive aspects of problem solving. In L. Resnick (Ed.), The nature of intelligence (pp. 231-236). NJ: Erlbaum, Hillsdale, 1976.

[38] J. H. McMillan, S. Schumacher. Research in education evidence-based inquiry ( 6 th ed), Pearson Education, Boston, 2006.

[39] J. Meijera, M. V. J. Veenman, B. H. A. van Hout-Wolters, M. Metacognitive activities in text-studying and problem-solving: development of a taxonomy, Educational Research and Evaluation, Vol.12, No.3, 209-237. 2006.

[40] J. M. Wilburne. The effect of teaching metacognitive strategies to preservice elementary school teachers on their mathematical problem solving achievement and attitude. (Doctoral Thesis). Philadelphia: Temple University. 1997.

[41] J. P. King. Matematik sanatı (18. Basım). Tübitak Popüler Bilim Kitapları, Ankara, 1992.

[42] J. Wilson. The Nature of Metacognition: What do primary school problem solvers do? In D. Barwood, D. Greaves, \& P. Jeffery (Eds.), Teaching numeracy and literacy: Interventions and strategies for "at risk" students (pp. 283-294). Australian Resource Educators' Association, Coldstream, Victoria, 1999.

[43] J. Wilson, D. Clarke. Towards the modelling of mathematical metacognition, Mathematics Education Research Journal, Vol.16, No.2, 25-48. 2004.

[44] K. Maaß. Modelling in class: What do we want the students to learn? In C. Haines, P. Galbraith, W. Blum \& S. Khan (Eds.), Mathematical modeling, ICTMA 12, Education, engineering and economics (pp. 63- 78). Horwood Publishing, Chichester, UK, 2007.

[45] K. Maaß. What are modelling competencies? Zentralblatt Für Didactik Der Mathematic, Vol.38, No.2, 113-142. 2006.

[46] Lai, E. R. (2011). Metacognition: A Literature Review, 2011, Online available from http://images.pearsonassessments.com /images/tmrs/Metacognition_Literature_Review_Final.pdf Publishers.

[47] M. B. Miles, A. M. Huberman. Qualitative data analysis: an expanded sourcebook. (2nd Edition), SAGE Publications, California, 1994.

[48] M. Bannert, C. Mengelkamp. Assessment of metacognitive skills by means of instruction to think aloud and reflect when prompted. Does the verbalisation method affect learning? Metacognition Learning, No.3, 39-58. 2008.

[49] M. Carlson, I. Bloom. The cyclic nature of problemsolving: An emergent multi-dimensional problem-solving framework, Educational Studies in Mathematics, Vol.58, No.1, 45-75. 2005.

[50] M. Q. Patton. Qualitative research \& evaluation methods (3th ed.), SAGE Publications, USA, 2002.

[51] M. V. J. Veenman. Kennis en vaardigheden; Soorten kennis een vaardigheden die relevant zijn voor reken-wiskunde taken. [Knowledge and skills that are relevant to math tasks]. In A. Andeweg, J. E. H. van Luit, M. V. J. Veenman, \& P. C. M. Vendel, (Eds.), Hulp bijleer problemen; Rekenen-wiskunde (pp. G0050.1-13). Kluwer, Alphen a/d Rijn, 1998.

[52] M. V. J. Veenman. The assessment of metacognitive skills: What can be learned from multi-method designs? In C. Artelt \& B. Moschner (Eds.), Lernstrategien und Metakognition: Implikationen für Forschung und Praxis (pp. 75-97). Waxmann, Berlin, 2005.

[53] M. V. J. Veenman. The role of intellectual and metacognitive skills in math problem-solving. In A. Desoete \& M. V. J. Veenman (Eds.), Metacognition in mathematics education (pp. 35-50). Nova Science Publishers, New York, 2006.

[54] M. V. J. Veenman, B. H. A. M. Van Hout-Wolters, P. Afflerbach. Metacognition and learning: conceptual and methodological considirations, Metacognition Learning, No.1, 3-14. 2006.

[55] M. V. J. Veenman, R. Kok, J. Kuilenburg. Intelligence and metacognitive skillfulness in secondary education. In F. Oser \& U. Baets (Eds.), 9th European Conference on Learning and Instruction, Abstract Volume (pp. 166). Mainz, Aachen, 2001.

[56] M.G. Voskoglou. The use of mathematical modelling as a tool for learning Mathematical. Quaderni di Ricerca in Didattica,

2006, Online available from http://www.math.unipa.it/ grim /quad16_voskoglou_06.pdf adresinden alındi.

[57] MEB. İlköğretim matematik 6-8. sınıflar öğretim programı ve kılavuzu, T.C. Milli Eğitim Bakanlığı, Ankara, 2009.

[58] MEB. Ortaöğretim matematik dersi $(9,10,11$ ve 12. sinıflar) öğretim programı, T.C. Milli Eğitim Bakanlığı, Ankara, $2013 b$.

[59] MEB. Ortaokul matematik dersi (5, 6, 7 ve 8. sınıflar) öğretim programı, T.C. Milli Eğitim Bakanlığı, Ankara, 2013a.

[60] N. F. Ellerton. Metacognitive benefits accruing from teacher education students' reflections on problem solving. In H. S. Dhindsa, L. S. Bee, P. Achleitner, \& M. A. Clements (Eds.), Studies in science, mathematics and technical education (pp. 202-211). Brunei Darussalam: Universiti Brunei Darussalam, Gadong, 2003.

[61] National Council of Teachers of Mathematics [NCTM]. Curriculum and evaluation standards for school mathematics, VA: Author, Reston, 1989.

[62] National Council of Teachers of Mathematics [NCTM]. Principles and standards for school mathematics, VA: Author, Reston, 2000.

[63] P. Biccard, D. C. J. Wessels. Problem-centred teaching and modelling as bridges to the $21 \mathrm{st}$ century in primary school mathematics classrooms, Online available from http://directo rymathsed.net/download/Biccard.pdf, 2011a.

[64] P. Biccard, D. C. J. Wessels. Documenting the development of modelling competencies of grade 7 mathematics students. G. Kaiser, W. Blum, R. B. Ferri ve G. Stillman (Ed.), Trends in teaching and learning of mathematical modelling içinde (s. 375-385). New York: Springer, $2011 \mathrm{~b}$.

[65] P. Galbraith, N. Clatworthy. Beyond standard models-meeting the challenge of modeling, Educational Studies in Mathematics, Vol.21, 137-163. 1990.

[66] P.D. Goldberg, W.S. Bush. Using metacognitive skills to improve 3rd graders' math problem solving. Focus on 
Learning Problems in Mathematics. Fall, 2003.

[67] P. R. Pintrich. The role of metacognitive knowledge in learning, teaching, and assessment, Theory into Practice, Vol.41, No.4. 2002.

[68] R. Akbaria, M. Khayerb, J. Abedi. Studying effect of educating state metacognition on learning mathematics, Reef Resources Assessment and Management Technical Paper, vol.40, No.2, 220-229. 2014.

[69] R. Borromeo-Ferri. On the influence of mathematical thinking styles on learners' modeling behavior, J Math Didakt, No.31, 99-118. 2010

[70] R. Borromeo-Ferri. Theoretical and empirical differentiations of phases in the modelling process, Zentralblatt für Didaktik der Mathematik, Vol.38, No.2, 86-95. 2006.

[71] R. K. Yin. Case study research: design and methods (3rd ed), CA: Sage, Thousand Oaks, 2003.

[72] R. Lesh, F. K. J. Lester, M. Hjalmarson. A models and modeling perspective on metacognitive functioning in everyday situations where problem solvers develop mathematical constructs. In R. Lesh \& H. Doerr, (Eds.), Beyond constructivism: Models and modeling perspectives on mathematics problem solving, learning and teaching (pp. 383- 403). NJ: Erlbaum, Mahwah, 2003.

[73] R. Lesh, G. Harel. Problem solving, modeling, and local conceptual development, Mathematical Thinking and Learning: An International Journal, Vol.5, No.2/3, 157-190. 2003.

[74] R. Lesh, H. M. Doerr. Foundations of a models and modelling perspective on mathematics teaching, learning and problem solving. In R. Lesh \& H. Doerr, (Eds.), Beyond constructivism: Models and modeling perspectives on mathematics problem solving, learning and teaching (pp. 3-
33). NJ: Erlbaum, Mahwah, 2003.

[75] R. Spruce, L. Bol. Teacher beliefs, knowledge, and practice of self-regulated learning, Metacognition Learning, No.10, 245277. 2015.

[76] R. Sternberg. Metacognition, abilities, and developing expertise: What makes an expert student? Instructional Science, Vol.26, No.1, 127-140. 1998.

[77] S. Kanadlı, Y. Sağlam. Is metacognitive strategies effective in problem solving? Elementary Education Online, Vol.12, No.4, 1074-1085. 2013.

[78] S. Kistner, K. Rakoczy, B. Otto, C. Dignath-van Ewijk, G. Buttner, E. Klieme. Promotion of selfregulated learning in classrooms: Investigating frequency, quality, and consequences for student performance, Metacognition and Learning, 5, 157-171. 2010.

[79] S. Merriam. Qualitative research and case study applications in education, John Wiley, New York, 2007.

[80] V. Geiger, P. Galbraith. Developing a diagnostic framework for evaluating student approaches to applied mathematics, International Journal of Mathematics, Education, Science, and Technology, No.29, 533-559. 1998.

[81] Y. Takahashi, A. Murata. Role of metacognition to promote strategy transfer in problem solving, IEEE Xplore Conference, Tucson, 07-10 Oct 2001.

[82] X. Lin, D. L. Schwartz, G. Hatano. Toward teachers' adaptive metacognition. Educational psychologist, Vol.40, No.4, 245-255. 2005.

[83] Z. Ç. Özcan. The relationship between mathematical problem solving skills and self-regulated learning through homework behaviours, motivation, and metacognition, International Journal of Mathematical Education in Science and Technology, No.46, 1-13. 2015. 